\title{
Unravelling the interplay of primary school teachers' topic- specific epistemic beliefs and their conceptions of inquiry-based learning in history and science
}

\author{
Athina Koutsianou et Anastassios Emvalotis
}

Department of Primary Education, University of Ioannina, Greece

\begin{abstract}
Article received 27 December 2020 / Article revised 6 September 2021 / Accepted 16 September / Available online 21 October
\end{abstract}

\begin{abstract}
Inquiry-based learning remains both an important goal and challenge for primary school teachers within and across different subjects, such as history and science. By addressing primary school teachers, for the first time, as both learners who deal with controversial topics and teachers who have significant teaching experience, this study aims to unravel the interplay between teachers' topic-specific epistemic beliefs and their conceptions of inquiry-based learning in history and science. Fifteen primary school teachers from Greece participated in this exploratory study through scenario-based semi-structured interviews. Data were analysed through a qualitative content analysis by applying both deductive and inductive approaches. The results of this study revealed the complex nature of teachers' epistemic beliefs and the necessity of using a nuanced approach to elicit their epistemic belief patterns in the context of working on a task. Further, this study revealed an overview of teachers' conceptions of inquiry-based learning in both history and science, by giving voice to teachers' thoughts and reasoning. But most importantly, the interplay between the two constructs was unravelled, indicating a complex connection between teachers' epistemic belief patterns and their conceptions of inquiry-based learning. Overall, it could be argued that the more availing the teachers' epistemic beliefs, the more thoroughly they conceive inquiry-based learning. Similarities and differences between history and science were also detected. Theoretical, empirical, and educational implications are discussed in an attempt to support primary school teachers involve themselves, and then their students, in an active process of knowing by applying helpful epistemic criteria.
\end{abstract}

Keywords: epistemic beliefs; inquiry-based learning; primary school teachers; history; science 


\section{Introduction}

The increasing challenges of the $21^{\text {st }}$ century require citizens to think critically and make informed decisions about everyday complex and usually controversial issues, such as the consumption of genetically modified food or the use of artificial intelligence products (Greene \& Yu, 2016; Sinatra \& Hofer, 2016). In order to support students in addressing such challenges, there are many calls worldwide for changes in educational systems both in terms of natural- and social-science subjects (e.g., European Commission, 2015; NCSS, 2010, 2018; NGSS Lead States, 2013; NRC, 2012). Specifically, teachers are asked to engage their students in epistemic practices that experts from different academic domains adopt to produce knowledge: such as interpretation and integration of multiple sources in history; experimentation and argumentation in science (Greene \& Yu, 2016; Sinatra, 2016). Through such practices, teachers can guide students to construct and evaluate their own and others' knowledge claims about specific topics (Greene \& Yu, 2016, p. 49). In broader terms, teachers are called to apply inquiry-based learning (IBL) as an instructional approach to engage their students in authentic scientific processes through a set of inquiry phases (e.g., Dobber, Zwart, Tanis, \& van Oers, 2017; Pedaste et al., 2015), which incorporate the epistemic practices above.

However, in-service teachers often struggle to implement such practices and foster IBL, due to many internal and external factors, especially primary school teachers who are trained as generalists and asked to teach various subjects, such as mathematics, literacy, science, history, and citizenship (Avraamidou, 2017; Gillies \& Nichols, 2015; Greene \& Yu, 2016; Levy, Thomas, Drago, \& Rex, 2013; van Uum, Verhoeff, \& Peeters, 2016). A large body of theory and research indicates that teachers' beliefs are important internal factors that shape their teaching actions (see Buehl \& Beck, 2015; Fives \& Buehl, 2012, 2016). According to Fives and Buehl (2017), teachers' beliefs are conceptualised as part of an integrated multidimensional system that also includes connected conceptions and values that "govern (their) cognitive and external actions" (p. 26). Specifically, teachers' beliefs about knowledge, learning and teaching are considered to be the internal factors which function as filters for new information, frames of salient tasks and guides of their actions (see Fives \& Buehl, 2012, 2016, 2017); and thus, support or hinder them from applying innovative teaching practices and new curriculum standards (Feucht, 2011; Fives \& Buehl, 2012, 2016; Greene \& Yu, 2016).

Teachers' epistemic beliefs or teachers' broader epistemic cognition, in particular, are at the forefront of the current literature (e.g., Buehl \& Fives, 2016; Feucht, Lunn Brownlee, \& Schraw, 2017; Lunn Brownlee, Ferguson, \& Ryan, 2017; Schraw, Lunn Brownlee, Olafson, \& Vanderveldt, 2017) as one aspect of this complex system, supporting their crucial but also salient role in both learning how to teach and teaching praxis. There is growing evidence to suggest that teachers' beliefs about the nature of knowledge and knowing (i.e., epistemic beliefs) mediate how they conceive learning and teaching, and further, how they engage in teaching. Nevertheless, in-service primary school teachers' epistemic beliefs have not been explored while they personally deal with the diversity and complexity of knowledge within topics from different academic domains, such as history and science. From another perspective, in order for primary school teachers to foster IBL in the context of such different subjects, a deep understanding of what IBL is and how it can be achieved within the classroom is also required (e.g., Ireland, Watters, Brownlee, \& Lupton, 2012; Levy et al., 2013; van Uum et al., 2016; Voet \& De Wever, 2016). But how do in-service primary school teachers conceive IBL within such different subjects as history and science is another underexplored aspect of this complex system.

Framed within different kinds of literature as epistemic cognition, teachers' beliefs, science and history education, this study attempts to unravel the interplay between in-service primary school teachers' topic-specific epistemic beliefs and their conceptions of IBL in history and science education. By addressing primary school teachers, firstly, as learners who deal with two controversial topics and then as teachers who articulate how they conceive IBL within different subjects, this study aims to get greater insight into teachers' internal factors that might motivate or prevent them from engaging their students in IBL. Further, this study addresses important conceptual and measurement issues regarding 
teachers' epistemic beliefs by applying an integrative theoretical framework and addressing them as learners in the context of working on a task.

\section{Theoretical background}

\subsection{Epistemic beliefs: an integrative theoretical framework}

Epistemic cognition and personal epistemology are two umbrella terms that have been used extensively to merge different but also related theoretical constructs (see Greene, Sandoval, \& Bråten, 2016b, 2016c; Hofer \& Bendixen, 2012; Hofer \& Pintrich, 1997, 2002). These constructs represent a large and heterogeneous body of theory and research regarding "how people acquire, understand, justify, change, and use knowledge in formal and informal contexts" (Greene, Sandoval, \& Bråten, 2016a, p. 1). Nowadays, the terms epistemic cognition and epistemic beliefs are the most predominant (Sinatra, 2016), though there is no consensus about their definition (Hofer, 2016; Greene et al., 2016a). Epistemic beliefs are mostly described as individuals' beliefs about the nature of knowledge (i.e., what knowledge is) and knowing (i.e., how one comes to know) (Hofer \& Pintrich, 1997). Besides, epistemic cognition is conceptualised as a broader construct encompassing all kinds of explicit and tacit cognitive processes related to epistemic or epistemological matters (Chinn, Buckland, \& Samarapungavan, 2011, p. 141).

Furthermore, it is not conclusive whether epistemic beliefs are part of the broader construct of epistemic cognition or whether they are distinct but related constructs, depending often on the adopted conceptual framework (Greene et al., 2016a; Greene, Yu, \& Copeland, 2014; Hofer, 2016; Sinatra, 2016). Based primarily on theory and research with students from primary school to university, a proliferation of models of epistemic beliefs and epistemic cognition has emerged, revealing conceptual confusion, but also the developmental path of this interdisciplinary field (see Greene et al., 2016b, 2016c). In short, the existing models can be broadly organised into three theoretical approaches or can be seen as a result of their integration: the developmental, multidimensional and contextual (or later situated) approach (see Hofer, 2016 for an updated review). Moreover, the dominant way of measuring epistemic beliefs and epistemic cognition, self-report instruments, are followed by numerous limitations and criticism (see Mason, 2016 for a review), which cast doubt on a large part of the existing research findings (see Greene \& Yu, 2014). Another important issue pertains to the degree of specificity of epistemic beliefs and epistemic cognition (Hofer, 2016; Mason, 2016). Although this line of research started by considering epistemic beliefs and epistemic cognition as more domain-general, there is also a proliferation of models and frameworks supporting the domain-, topic-, task-specific or even the situated nature of these constructs based on empirical evidence (e.g., Chinn et al., 2011; Greene et al., 2016c; Hammer \& Elby, 2002; Merk, Rosman, Muis, Kelava, \& Bohl, 2018; Muis, Bendixen, \& Haerle, 2006; Sandoval, 2005).

Framed within this ever-growing literature of learners' epistemic cognition, a lot of studies have investigated both pre- and in-service teachers' epistemic beliefs about teaching knowledge (e.g., Buehl \& Fives, 2009), specific academic domains (e.g., Guilfoyle, McCormack, \& Erduran, 2020; Voet \& De Wever, 2016) or even topics (e.g., Feucht, 2011, 2017; Merk et al., 2018). In addition, teachers' epistemic beliefs have frequently been operationalised through aspects of teaching and learning, resulting in a partial overlap with their beliefs about teaching and learning (Maggioni, VanSledright, \& Alexander, 2009; Muis \& Foy, 2010; Olafson \& Schraw, 2010). More recently, frameworks have been developed for conceptualising: a) the complex nature of teachers' epistemic cognition regarding both learning to teach and teaching praxis (e.g., Buehl \& Fives, 2016); and, b) potential mechanisms for changing teachers' epistemic cognition in action (e.g., Feucht et al., 2017; Lunn Brownlee et al., 2017). However, in-service teachers' epistemic beliefs in the context of dealing with challenging issues as learners seem to have been overlooked empirically (VanSlendright \& Maggioni, 2016), followed by conceptual confusion and measurement limitations. Attempting to address this gap, the present study 
adopted an integrative theoretical framework to both conceptualise and approach primary school teachers' epistemic beliefs probed within the context of controversial topics in history and science.

In more detail, the integrative framework of epistemic beliefs applied in this study consists of four dimensions (i.e., the certainty and structure of knowledge, indicating the nature of knowledge; and the source of knowledge and justification of knowing, indicating the nature of knowing) which are interrelated in a relatively coherent system; and three perspectives (i.e., absolutism, multiplism and evaluativism) through which people understand the content of each dimension. Table 1 presents a thorough description of the applied framework. This framework was developed based on Feucht's $(2011,2017)$ framework which integrated the dimensional and developmental frameworks proposed by Hofer (2001) and Kuhn (1999), and by incorporating further elaborated descriptions of these dimensions and perspectives derived from the literature (Barzilai \& Weinstock, 2015; Bendixen, Winsor, \& Frazier, 2017; Chinn et al., 2011; Hofer, 2000; Hofer \& Pintrich, 1997; King \& Kitchener, 1994; Kuhn, Iordanou, Pease, \& Wirkala, 2008; Kuhn \& Weinstock, 2002). Such a nuanced approach of epistemic beliefs enables the recognition of unique epistemic belief patterns rather than simply categorising teachers' epistemic beliefs as naïve or sophisticated for each dimension, which is quite a common limitation (Feucht, 2011, 2017; Mason, 2016; Merk et al., 2018). Moreover, the terms "less availing" and "more availing" were chosen (Muis, 2004) to describe teachers' beliefs across three perspectives, from absolutism to multiplism and evaluativism in an attempt to avoid making unnecessary assumptions about their value (Greene et al., 2016c). 
Table 1

Conceptualisation of epistemic beliefs: an integrative framework of 4 dimensions and 3 perspectives

\begin{tabular}{|c|c|c|c|}
\hline Dimensions & & Perspectives & \\
\hline & Absolutism & Multiplism & Evaluativism \\
\hline $\begin{array}{l}\text { Certainty of } \\
\text { knowledge }\end{array}$ & $\begin{array}{l}\text { Knowledge about this topic is (absolutely) } \\
\text { certain and stable. }\end{array}$ & $\begin{array}{l}\text { Knowledge about this topic is (completely) } \\
\text { uncertain, constantly changing and evolving. }\end{array}$ & $\begin{array}{l}\text { Knowledge about this topic is uncertain and } \\
\text { evolving/cannot be obtained with (absolute) }\end{array}$ \\
\hline $\begin{array}{l}\text { Knowledge as a more } \\
\text { or less certain and } \\
\text { stable product }\end{array}$ & $\begin{array}{l}\text { Knowledge about this topic can be obtained } \\
\text { with (absolute) certainty at some future } \\
\text { point (in temporary uncertainty). (Cert*A) }\end{array}$ & $\begin{array}{l}\text { Knowledge about this topic cannot be obtained with } \\
\text { certainty at any future point. }(\text { Cert*M) }\end{array}$ & $\begin{array}{l}\text { certainty, but it is possible to improve the } \\
\text { degree of certainty at some future point. } \\
\text { (Cert*E) }\end{array}$ \\
\hline $\begin{array}{l}\text { Structure of } \\
\text { knowledge } \\
\text { Knowledge as a more } \\
\text { or less abstract and } \\
\text { structured product }\end{array}$ & $\begin{array}{l}\text { Knowledge about this topic is seen as an } \\
\text { accumulation of objective and rather } \\
\text { independent facts (e.g., concrete data or } \\
\text { concepts) that are correct or incorrect in } \\
\text { their representation of reality. (Stru*A) }\end{array}$ & $\begin{array}{l}\text { Knowledge about this topic is seen as a set of } \\
\text { personal and subjective opinions (i.e., knowledge as } \\
\text { an abstraction, not limited to concrete data), that are } \\
\text { accountable only to their owners and possibly } \\
\text { connected with others. (Stru*M) }\end{array}$ & $\begin{array}{l}\text { Knowledge about this topic is seen as a set of } \\
\text { judgments based on evidence (e.g., theories, } \\
\text { explanations and interpretations) which are } \\
\text { complex and highly interrelated. (Stru*E) }\end{array}$ \\
\hline $\begin{array}{l}\text { Source of knowledge } \\
\text { Knowing as a more or }\end{array}$ & $\begin{array}{l}\text { Knowledge comes from external and } \\
\text { objective sources outside the self. }\end{array}$ & $\begin{array}{l}\text { Knowledge is generated by human minds within the } \\
\text { self. }\end{array}$ & $\begin{array}{l}\text { Knowledge is generated by human minds, } \\
\text { anchored in standards of what counts as }\end{array}$ \\
\hline $\begin{array}{l}\text { less active process of } \\
\text { acquiring knowledge }\end{array}$ & Knowledge is passively perceived through & Knowledge is actively formed based on internal and & reliable knowledge, outside and within the self. \\
\hline & $\begin{array}{l}\text { external sources/is transmitted (i.e., people } \\
\text { seeking the source of their knowledge } \\
\text { outside themselves). (Sour*A) }\end{array}$ & $\begin{array}{l}\text { subjective sources (i.e., knowledge is filtered } \\
\text { through the perceptions of the person making an } \\
\text { interpretation; hence, what is known is limited by } \\
\text { the perspective of the knower). (Sour*M) }\end{array}$ & $\begin{array}{l}\text { Knowledge is actively constructed based on the } \\
\text { integration of internal and external sources, } \\
\text { usually, in interaction with others. (Sour*E) }\end{array}$ \\
\hline $\begin{array}{l}\text { Justification of } \\
\text { knowing } \\
\text { Knowing as a process }\end{array}$ & $\begin{array}{l}\text { Knowledge requires no justification since } \\
\text { one must only "observe" to know (i.e., first- } \\
\text { hand experience). }\end{array}$ & $\begin{array}{l}\text { Knowledge is justified by giving reasons and using } \\
\text { evidence, but the criteria are idiosyncratic to the } \\
\text { individual (e.g., choosing the arguments and }\end{array}$ & $\begin{array}{l}\text { Knowledge is justified based on criteria of } \\
\text { argument and evidence, in terms of what is } \\
\text { most reasonable or probable based on current }\end{array}$ \\
\hline $\begin{array}{l}\text { of evaluating } \\
\text { knowledge claims }\end{array}$ & $\begin{array}{l}\text { Knowledge is justified based on absolute } \\
\text { criteria (e.g., right or wrong) or based on } \\
\text { authority and experts. (Sour*A) }\end{array}$ & $\begin{array}{l}\text { evidence that fit a personal opinion, preference, } \\
\text { experience or judgment). (Just*M) }\end{array}$ & $\begin{array}{l}\text { evidence; and it is re-evaluated when relevant } \\
\text { new evidence, perspectives, or tools of inquiry } \\
\text { become available (i.e., based on the rules of } \\
\text { inquiry in different domains). (Just*E) }\end{array}$ \\
\hline
\end{tabular}




\subsection{Primary school teachers' conceptions of IBL: an underexplored area}

According to Fives, Lacatena, and Gerard's (2015) systematic literature review (from a contentgeneral perspective), there is much inconsistency in how researchers define and approach teachers' beliefs about (or conceptions of) ${ }^{1}$ teaching and learning, leading usually to the choice of dichotomising beliefs along a continuum of transmissionist (teacher-centred) to constructivist (student-centred) approaches. However, this categorisation is too broad to capture meaningful nuances, followed by conceptual issues. For instance, even though "constructivism" is a theory of learning according to which students learn by constructing their knowledge (see also Windschitl, 2002), it has often been misused as a theory of teaching as well. In their review, Fives et al. (2015) concluded that very few studies have focused directly on teachers' beliefs about learning (e.g., Chan, 2011), including within specific academic domains (e.g., Tsai, 2002), regardless of their role in teaching practice in conjunction with teachers' beliefs about teaching. With regard to in-service teachers' conceptions of IBL, the existing research is very limited and mainly localised in science education (however, see Voet \& Wever, 2016 for an example in history education).

According to Levy et al. (2013), the definition of IBL may differ even within the same subject, such as science and history education. In general terms, however, IBL can be defined as an educational strategy according to which students are actively engaged in methods and practices similar to those that experts apply to produce knowledge (Pedaste et al., 2015), such as experimentation and argumentation (Greene \& Yu, 2016; Sinatra, 2016). Several studies in science education have focused on how teachers conceive scientific inquiry (e.g., Bartos \& Lederman, 2014; Windschitl, 2004) and classroom inquiry (e.g., Kang, Orgill, \& Crippen, 2008), or how they implement IBL in action based either on classroom observations (e.g., Forbes, Biggers, Zangori, 2013) or on teachers' self-reports (e.g., Lakin \& Wallace, 2015) and self-reflections (e.g., Gillies \& Nichols, 2015; Seung, Park, \& Yung, 2014). Most of these studies though pertain to pre-service teachers or in-service secondary science teachers, and a common way of analysing their conceptions and practices of IBL is based on the detection of essential features proposed by science education standards, including engaging in scientifically oriented questions and formulating explanations based on evidence (e.g., NGSS Lead States, 2013; NRC, 2012). Ireland et al. (2012), on the other hand, avoided using such a predefined coding scheme and terminology and applied a phenomenographic analysis to qualitatively categorise in-service primary school teachers' reported experiences of teaching for inquiry learning in science. Based on teachers' interviews, the researchers revealed three prevailing conceptions: the experience-centred conception where teachers mainly engage their students in sensory activities; the problem-centred conception where teachers mainly involve their students in solving challenging problems; and the question-centred conception where teachers mainly support their students to ask and answer their questions (pp. 166-169).

On the other hand, even though there is an equivalent interest in applying IBL in history education (Levy et al., 2013; Martell, 2020), research on teachers' conceptions of IBL is very scarce (see Voet \& De Wever, 2016); especially with regard to primary school teachers, no relevant study was detected in the literature. Specifically, Voet and De Wever (2016) explored in-service secondary history teachers' beliefs about the nature of history and teaching history, their interplay, and further potential contextual influences in order to gain a greater overview of teachers' conceptions of IBL. Based on teachers' interviews, the researchers also revealed three availing conceptions, IBL as: understanding by collecting more information about a given topic; evaluating critically more information about a given topic to find the right answer; and, investigating by generating questions within a given topic, analysing information and forming arguments (pp. 61-62).

Finally, it is worth mentioning Levy et al.'s (2013) endeavour to compare and contrast conceptions of IBL in science, history and English education in order to outline cross-disciplinary conceptions of IBL by combining their conceptions with the findings of their previous studies with pre- or in-service teachers of each domain. In short, they concluded that even though a singular definition may be elusive and conceptions of IBL can vary even within each subject, there are common components. That is, teachers are asked to support their students to ask and answer questions based on data, and to justify 
explanations about the phenomena under investigation. Framed within this underexplored research area, this study attempts to produce an overview of in-service primary school teachers' conceptions of IBL both in history and science education, in order to offer a new perspective on the existing literature.

\subsection{The interplay of teachers' epistemic beliefs and conceptions of IBL}

Many studies, especially in science education, have explored the relation of teachers' epistemic beliefs with different constructs situated in teaching practice, including: teachers' conceptions of teaching and learning in general (e.g., Chan, 2011; Cheng, Chang, Tang, \& Cheng, 2009); their selfreported or applied practices in science teaching (e.g., Kang, 2008; Tsai, 2007); and both their conceptions and practices in science teaching (e.g., Lee \& Tsai, 2011). In general, these studies suggest that teachers' epistemic beliefs are connected somehow with their conceptions of teaching and learning, and further, with their teaching practices; even though these relationships are not linear but very complex (for a comprehensive review see Buehl \& Beck, 2015). Additionally, a common claim found in this literature is that the more "sophisticated" the teachers' epistemic beliefs, the more "constructivist" approaches they support, and vice versa. However, such findings are not considered well-documented because of the many conceptual and measurement limitations, which come with the existing literature (see also 2.1. and 2.2. Sections).

The interplay between teachers' epistemic beliefs and conceptions of IBL has been directly examined by Voet and De Wever (2016), through the perspective of history teachers in secondary education. In short, their study revealed that although most history teachers appeared to hold criterialist (i.e., evaluativist) beliefs about the interpretive nature of history, only a few described IBL through the lenses of a full historical inquiry, indicating a misunderstanding of inquiry practices that lie at the core of this domain. However, a much clearer connection was found between teachers' beliefs about the nature of history and history teaching in general. By adopting a much more detailed approach of epistemic beliefs, and through the perspective of primary school teachers, this study attempts to unravel this interplay within two academic domains and the corresponding primary school subjects, history and science.

\section{Research questions}

In this study, the following research questions were addressed:

1. What are participants' epistemic beliefs while dealing with two controversial topics in history and science?

2. What are participants' conceptions of IBL in history and science education?

3. Are there any differences in participants' epistemic beliefs and conceptions of IBL between history and science?

4. How are participants' topic-specific epistemic beliefs related, if at all, with their conceptions of IBL in history and science education?

\section{Methods}

\subsection{Participants and research design}

A qualitative research design was adopted to unravel the interplay of primary school teachers' epistemic beliefs and conceptions of IBL, without aiming to generalise the findings of this study 
(Merriam, 2009). Given the exploratory nature of this study, the snowball sampling was applied (Creswell, 2015) by setting the prerequisite that participants had taught at least one school year of the $6^{\text {th }}$ grade of primary education (i.e., 11-year-old students). In total, 15 primary school teachers from three different counties in Greece agreed to take part in semi-structured interviews with the first author, during the spring semester of the school year 2018-2019. The condition of having taught in the $6^{\text {th }}$ grade was set to ensure that all teachers were familiar with both the historical and scientific topics used in their interviews, as well as aiming to teach history and science through IBL based on the current curricula in Greek primary education. After being informed about the research procedure, the confidential use of the collected data and participants' right to withdraw from the interview at any time, teachers who gave their consent participated in this study voluntarily and anonymously. There was also an attempt to make participants feel comfortable enough to avoid having to reply in a socially desirable way, by explaining that there were no right and wrong answers.

In total, eight teachers were female and seven were male, with the mean age being 47.6 years (SD $=5.87$ years). Twelve teachers had completed a four-year bachelor's degree programme at university, for teaching all the basic subjects in primary education (e.g., literacy, mathematics, science and history). Five of these teachers had also completed master studies in education, one also had a four-year bachelor and a master degree in computer science (Teacher 11), and another teacher also had a four-year bachelor degree in pre-school education (Teacher 14). One teacher was a master student when this study took place. All six teachers with master studies had some research experience in the context of their thesis. The other three teachers held a degree of a two-year training programme at a pedagogical academy for teaching all the basic subjects in primary education as well. Participants' teaching experience in primary education ranged from 12 to 32 school years, and teaching experience in the $6^{\text {th }}$ grade in particular, ranged from one to 16 school years. Their teaching experience ensured that they had a lot of opportunities to reflect on their beliefs about knowledge, teaching and learning in the context of the school classroom. Table 2 presents the demographic characteristics of the participants in detail.

Table 2

Demographic characteristics of participants $(n=15)$

\begin{tabular}{lccccc}
\hline Participant & Gender & Age & Level of education & $\begin{array}{c}\text { Teaching } \\
\text { experience in } \\
\text { the 6th grade }\end{array}$ & $\begin{array}{c}\text { Total } \\
\text { teaching } \\
\text { experience }\end{array}$ \\
\hline Teacher 1 & M & 51 & 4-year bachelor degree & 12 & 21 \\
Teacher 2 & F & 53 & 2-year bachelor degree & 16 & 23 \\
Teacher 3 & M & 51 & 4-year bachelor degree \& master student & 4 & 15 \\
Teacher 4 & F & 52 & 4-year bachelor degree \& master degree & 10 & 24 \\
Teacher 5 & M & 49 & 4-year bachelor degree & 11 & 22 \\
Teacher 6 & M & 52 & 2-year bachelor degree \& master degree & 8 & 26 \\
Teacher 7 & F & 48 & 4-year bachelor degree & 4 & 21 \\
Teacher 8 & M & 51 & 2-year bachelor degree & 6 & 23 \\
Teacher 9 & M & 44 & 4-year bachelor degree & 7 & 18 \\
Teacher 10 & F & 40 & 4-year bachelor degree & 1 & 16 \\
Teacher 11 & M & 37 & two 4-year bachelor degrees \& two master degrees & 1 & 12 \\
Teacher 12 & F & 43 & 4-year bachelor degree \& master degree & 3 & 18 \\
Teacher 13 & F & 54 & 2-year bachelor degree & 15 & 32 \\
Teacher 14 & F & 52 & two 4-year bachelor degrees \& master degree & 14 & 22 \\
Teacher 15 & F & 37 & 4-year bachelor degree & 3 & 15 \\
\hline
\end{tabular}

Notes. $\mathrm{F}=$ Female; $\mathrm{M}=$ Male. Age was measured in years and teaching experience in school years (i.e., 10 months). 


\subsection{Interview protocols and procedure}

Semi-structured interviews were conducted to elicit both participants' epistemic beliefs and conceptions of IBL (Cohen, Manion, \& Morrison, 2007; Merriam, 2009). Focusing on the construct of teachers' epistemic beliefs, two topics were chosen from the $6^{\text {th }}$-grade Greek textbooks of history and science: a) the governance of Ioannis Kapodistrias (the first governor of Greece during the period 18281831); and b) the orientation of the migratory birds (specifically, the European robins) based on Earth's magnetic field. These topics were selected because they are controversial according to the existing literature and so the condition was necessary in order to trigger teachers' epistemic beliefs within a task (Barzilai \& Weinstock, 2015; VanSledright \& Maggioni, 2016). For each topic, a scenario was developed by using two authentic historical (Kremmidas, 2015; Ploumidis, 2015) and scientific studies (Holland \& Helm, 2013; Wiltschko, Gehring, Denzau, Nießner, \& Wiltschko, 2014), which address the same topic differently and conclude in different explanations. Within this context, and handling each topic separately, participants were first asked to read both accounts and then answer a set of open-ended questions, aiming to elicit their epistemic beliefs as learners, implicitly and explicitly. For instance, teachers were asked to think about how they would go about making their own decision on each topic (this question aimed to prompt teachers' beliefs about the source of knowledge). Furthermore, they were asked to judge the different perspectives on each topic by mentioning specific criteria (this question aimed to prompt teachers' beliefs about the justification of knowing). The applied interview protocol was developed based on the adjustment and integration of existing open-ended questions derived from the literature (Barzilai \& Weinstock, 2015; King \& Kitchener, 1994; Kuhn \& Weinstock, 2002).

After finishing the aforementioned task for each topic, participants were asked to give a short description of how they would go about teaching this topic in their classroom with $6^{\text {th }}$-grade students, by putting more emphasis on the teaching process. In fact, this was a transitional question for shifting their attention from their role as learners (in the topic-specific level) to their role as teachers (in the domain-specific level). Focusing on the construct of the conceptions of IBL in history and science education, teachers were also asked to answer a set of indirect and direct open-ended questions. The applied interview protocol was developed based on Voet and De Wever's (2016) interview protocol regarding IBL in history education, in addition to certain clarifying questions (e.g., How would you define IBL in history/science education? What is the role of the students and what is your role in a lesson that focuses on IBL within history/science education?). After taking into account differences in the terminology between history and science, the questions were formulated to be equivalent. Both scenarios and interview protocols were first pilot tested with Greek experts in science and history, and primary school teachers, to further improve their wording and validity.

All interviews were conducted by the first author in Greek based on the aforementioned scenarios and interview protocols, which are provided translated in English in Appendices A1 and A2 respectively. The same procedure was applied twice with every participant for both topics and domains in a counterbalanced order. However, the researcher could deviate from the protocols as needed to help participants elaborate more on their thoughts via clarifying questions. Overall, the time duration of interviews ranged from 50.32 to 105.08 minutes per participant $(\mathrm{M}=71.32 \mathrm{~min}$., $\mathrm{SD}=17.51 \mathrm{~min}$.).

\subsection{Data analysis}

All interviews were audio-recorded, transcribed verbatim and coded through qualitative content analysis (Hsieh \& Shannon, 2005; Mayring, 2000) by using NVivo 12 software. Specifically, the collected data were analysed by applying both deductive and inductive approaches depending on the specific theoretical construct. Each interview was divided into codable segments and the segments that captured the meaning of participants' thoughts were defined as the units of analysis (Chi, 1997).

The analysis of data regarding teachers' epistemic beliefs was more deductive since there is a lot of relevant research. This happened by applying as a coding framework the integrative theoretical framework presented in Table 1. Hence, indicating all the combinations of dimensions and perspectives 
of epistemic beliefs per topic, 12 codes were generated in NVivo. Representative examples of these codes are included in Table 3. On the other hand, the analysis of data about teachers' conceptions of IBL was more inductive since there is less relevant research. This happened by elaborating existing categories from the literature (Ireland et al., 2012; Voet \& De Wever, 2016) according to participants' reasoning and thoughts. Table 4 describes these categories and gives representative examples.

The first author coded the interview data through a recursive process, by comparing and contrasting participants' quotations within each code and category of the epistemic beliefs and conceptions of IBL. The researcher attempted to be reflexive in every step of the data analysis to avoid forcing her own ideas about the two theoretical constructs on the data (Creswell, 2015; Greene \& Yu, 2014). In order to check the reliability of the results, the second author independently coded eight randomly selected interview transcripts, acting as a peer debriefer for the first author, given that the latter was not involved in the data collection and development of the coding frameworks. The intercoder agreement was $85 \%$ for teachers' epistemic beliefs and $92 \%$ for their conceptions of IBL. The different interpretations of the collected data, especially for the epistemic beliefs, were mainly because of the different types of beliefs expressed by the same participant throughout the interview. Thus, the two authors presented to each other their arguments behind their decisions on the data analysis, in order to discuss and resolve their discrepancies, resulting in 100\% intercoder agreement. 
Table 3

Representative examples of teachers' topic-specific epistemic beliefs in history and science (dimension*perspective)

Codes Example

History (Scenario topic: The governance of Ioannis Kapodistrias)

Cert*A Teacher 14: If someone sits down and searches whatever has been written for him, they will safely come to a conclusion. So, from this point of view, yes, but I don't know if there are sources. ... For me, historians do [know], so over here, this contrast is troubling me. Yes, historians do [know].

Cert*M Teacher 6: No way! It's too, too difficult. ... There is no certainty in history ... there is an approach, there is no certainty and the approach, how they say it, [it] depends on the school you are in, the historical school you are in ... you capture your own opinion, a historical opinion. There is no certainty.

Cert*E Teacher 4: Yes, with certainty yes, but to some extent. Absolutely, no. Absolutely no, because... Perhaps though, these historians who are more concerned with and read the sources, certainly they have a more specialised opinion and can express it. ... I think yes, that complete certainty no. Because, is it even possible that they have read all the relevant, all the critical sources that exist? ... But again, wouldn't the element of subjectivity exist inside? I think that there is always inside the historian. It always exists, no matter how objective they want to be.

Stru*A Teacher 15: [Knowledge] consists of the data we have, again as I said before, which are concrete because they are things and events that happened and have passed through written texts and from other sources... I can't think of anything else.

Stru*M (See the description of the Teacher 1 provided in the 5.3.1. Section of this article.)

Stru*E Teacher 8: [Knowledge structure] is not simple... in no case it is simple. It is rather a complex process... perhaps more complex than a common reader can afford, let's say, right? You read the work of a historian about a person for whom you know basic things, for his/her life, and you face a difficulty in understanding how they justified their opinion, how they integrate the facts and how they make it the knowledge that they want to offer. Because the historian after their research... I consider the result of their research to be the knowledge that they want to also offer to the public, right?

Sour*A Teacher 15: Well, I would try to focus on the data of each source that will help me to acquire a thorough opinion of his life and work, data in order to understand his personality and then ... about how he functioned in his politics, in this way.

Sour*M Teacher 6: I try to approach it as well ... because you can't have it, the truth especially in this thing, the truth exists, but we try to approach it, but we approach it from our own side, it is not possible; I will write, I have a 'load' inside me that I am carrying, that is, I say even if I lived [then] or Kapodistrias was my father, again I would have a load, I would write from my own side. In other words, there should be an objective observer who can see and record. Yes! ... But again, he/she would have his/her own perspective, right? It would be very difficult.

Sour*E Teacher 9: The events are always specific; the interpretation of the events is the one that differs each time. So, depending on what everyone classifies as the most important, they also express their opinion afterwards. ... Basically, I try to see it ... or at least gather information from as many sources as possible, and from as many people as possible, if I know people who are related to the topic. And beyond that, I try to ... judge, to draw my own conclusions, whether something is positive or not, or to what extent it is positive or not, let's say.

Just*A Teacher 13: The sources would count, I would only count the facts, the sources, I would not place my own opinion ... that is, without being placed, here both [historians] are placed. ... without historian's opinion.

Just*M Teacher 14: Logically, I will also be influenced by the teaching of history for so many years, let's say, with the one book that we have as a source. Also, some reading of mine about Kapodistrias and in general, he is one of the political people that I personally like; maybe because he was the first 
governor, maybe because he really made the first attempt to set up the education and, hence, make a fight for the country to deal with the primary sector. I believe my thinking has a reasonable basis, I believe, subjectively.

Just*E Teacher 3: What plays a role is whether everyone can justify it, their opinion. Of course, and the fact that I personally lack a lot of knowledge on this specific topic, maybe I am wrong based on my previous knowledge ... and tend to an opinion which ... is based on what I have as knowledge; and it is possible to be unjust to another opinion. Therefore, it is easy to get carried away based on your experiences and knowledge to think that one opinion may be more correct than the other, but the right and fair is, since there is justification on the other hand, as much as we do not like this view, to check it and investigate it in order to see if and to what extent it ... may be to the right direction. ... Criteria ... obviously, what I mainly pay attention to is to try to understand whether this [any historical account] can be appropriate at that time.

\section{Science (Scenario topic: The orientation of migratory birds based on the Earth's magnetic field)}

Cert*A Teacher 7: Of course, it's not so difficult that scientists cannot help us to certify it.

Cert*M Teacher 15: I find it very difficult ... because some things are ... inexplicable! We cannot determine everything based on physics and laws. ... As I told you before, I think that there are some things that, no matter how close we get, we cannot give a solution and answers to these issues.

Cert*E Teacher 5: Nor do I think that is absolute... Well ... now I think that ... if this research is repeated in different populations of robins and has results, at some point we will get to the point of talking about ... with greater certainty about the journey.

Str*A Teacher 14: [Knowledge consists] clearly of measurable results, that is, here you have to measure, have a result, the experiment must be specific, the experiment is not a theory. You apply, try and end up. Hypothesis, test and error, normally the course we have to do in science, so it goes by itself. ... Data mainly. And no interpretation of the data; measurement and after, they build the result, I believe.

Str*M (There was not found a representative example of this dimension*perspective regarding this topic.)

Str*E Teacher 8: [Knowledge consists of] too much research and the result of this research, right? And a practical result of this research. ... Definitely data ... Opinions because ... different people express different opinions. The more trained people are, the better and higher quality products they are based on. Their opinions are obviously better, and their interpretations as well, which are their perspicacity from there and beyond ... of everyone or how they will manage all this. ... Because the interpretations produce the results obviously, right? You observe a phenomenon, you experiment, but you must definitely interpret it and leave your consignment. This consignment can be theoretical, it can create a thousand ... more questions, but it can also be practical. So, the interpretation, for me, plays a very important role, [the interpretation] of the many big data and the different opinions.

Sour*A Teacher 3: [To make a decision is] very difficult because ... I don't have the proper knowledge to do it. Well, then, I couldn't take the place of one or the other, but I would just stay in the simple quotation of the research results.

Sour*M Teacher 6: The truth is one, which we try to approach, the same happens in history as well; the truth exists, we try to approach it and we perceive it with our perspective. I don't know. I can't answer. The truth exists, we cannot, we try to approach it but with our subjective way. Even researchers try to be objective but I don't know, since there are a lot of studies on this specific topic, I don't know where they can conclude and how they can support it, I don't know. ... I try to approach the topic as much as possible, to have a personal opinion.

Sour*E Teacher 8: I would read them once again. If I leaned towards one, I would look for it a little more and that might have attracted me to look for the other one a little more, and I would probably end up intuitively again and not scientifically. You know, [for] a scientific study, someone who is not a scientist but is a listener or a reader says after all, which one I like and not which one is the best, right? ... But obviously, the groups of scientists, who applied both methods, have their weapons in their arsenal, they are based on many things and since they have an outcome, maybe they are both... they answer a part of the question, which is what? How can they succeed and come and go in the same place, right? They don't lose their way, they know. 
Just*A Teacher 13: Depends on what data [the study] will have better, statistical data. ... I would look for more information to see the data.

Just*M Teacher 3: If it is close to what ... I have learned and ... it can affect me more, I would say ... the first opinion, and be able to understand it, right? To bring it at my cognitive level; it would suit me such a plausible [opinion], I would say that it is truer.... The only criterion I could adopt is this one ... what suits me best is what I have in my mind, that I have experienced, that is, my experiences ... that the magnet with the iron [are attracted], as I said before.

Just*E Teacher 8: In an ideal environment that happens to fall into my hands two scientific, different ... not opposite approaches; since I am interested in the topic, because if I was not interested, I would not read the approaches, right? [I would focus on] how the issues are posed and what results each study has. In this way I would weigh it, that is, yes, the whole project done, the experimental, research [project], but from the first one, these results were emerged, from the second one, maybe less or poor results [were emerged]. Obviously, I as a common mind as well, I would go ... I would judge as more well-justified ... the study that had more practical results perhaps? Perhaps [the study] that ... opened new ways? In other words, if, from the first study, ... they said that after the experiment with robins, the same experiment done with the canaries let's say ... and there were found corresponding results, obviously it would cover me more...

Notes . Cert = Certainty of knowledge; Stru = Structure of knowledge; Sour = Source of knowledge; Just $=$ Justification of knowing.

$\mathrm{A}=$ Absolutism; $\mathrm{M}=$ Multiplism; $\mathrm{E}=$ Evaluativism. The abbreviations, such as Cert*A, indicate all the different combinations of the four dimensions and three perspectives of epistemic beliefs: i.e., Cert*A indicates the certainty of knowledge and absolutism. 
Table 4

Teachers' conceptions of IBL in history and science education

\begin{tabular}{|c|c|c|c|}
\hline Category & Description & Participants & Representative excerpts \\
\hline \multicolumn{4}{|c|}{ In History Education } \\
\hline Understanding & $\begin{array}{l}\text { IBL is seen more as a practical way of } \\
\text { gathering information and sources in } \\
\text { order to better analyse and understand the } \\
\text { given topic. }\end{array}$ & $\begin{array}{l}2,10,13, \\
15\end{array}$ & $\begin{array}{l}\text { Teacher 2: [Students] should know how to read the text very well ... because if they cannot } \\
\text { read it correctly, they cannot understand it. From there on, they should isolate the facts, the } \\
\text { people and listen to what I tell them at school, but also investigate further, that is, search for } \\
\text { and bring opinions and information in the classroom.... [IBL is] that I ask my students to bring } \\
\text { the information, to gather all this and then, the main teaching begins, something like that I have } \\
\text { in my mind. Let them first investigate and, then, all together find the common goal. }\end{array}$ \\
\hline Evaluating & $\begin{array}{l}\text { IBL is seen more as a critical way of } \\
\text { learning how to compare and evaluate } \\
\text { different opinions and sources about the } \\
\text { same topic in order to realize their } \\
\text { subjectivity and develop critical thinking } \\
\text { skills. }\end{array}$ & $\begin{array}{l}1,3,4,5,7 \text {, } \\
9\end{array}$ & $\begin{array}{l}\text { Teacher 9: [With reference to the topic of the given scenario, students] should think on both } \\
\text { sides that historians support. And then, if they could find out if something is right, which is } \\
\text { right, which is wrong, and, basically, where they conclude. In other words, I would like to see } \\
\text { children's conclusions. ... [In IBL] students need to understand that they don't have to accept } \\
\text { whatever they read ... without thinking. The purpose of the school is to create children's ability } \\
\text { of critical thinking, be able to read three different sources for the same topic and choose, think; } \\
\text { that is, they should have created a critical way of thinking regarding what they read and from } \\
\text { there on ... they are led to knowledge and understanding. }\end{array}$ \\
\hline Investigating & $\begin{array}{l}\text { IBL is seen more as an active process } \\
\text { which resembles problem solving, by } \\
\text { generating questions, searching in the } \\
\text { literature, analysing information and } \\
\text { formulating arguments; in order to explain } \\
\text { a historical topic and eventually learn how } \\
\text { to proceed in order to answer their own } \\
\text { questions. }\end{array}$ & $\begin{array}{l}6,8,11,12, \\
14\end{array}$ & $\begin{array}{l}\text { Teacher 6: (He mentioned a lot the importance of local history.) You should find new ways, } \\
\text { new instructional tools outside the school ... so that they become the young researchers, to } \\
\text { search as much as they can. You will give them books, sources of the past as well.... They } \\
\text { should discover some things so that they can connect them with the local, with their own, with } \\
\text { what they perceive. ... [Regarding a historical topic,] you can go to search what is written in the } \\
\text { local newspapers. ... You can make them photographers, ask them to take photographs from the } \\
\text { old newspapers, this is a game at the same time and they really like it, right? ... [In IBL] } \\
\text { students should investigate and the teacher should be the research assistant. Of course, the } \\
\text { teacher should bear in mind that he should ask them what to look for, right? (In order to explain } \\
\text { his thoughts, he mentioned a lot of questions regarding the local history of his city, such as) } \\
\text { what statues, monuments are there in [this city]? For example, I will go again to the [Greek] } \\
\text { civil war, why are there only statues of one side and not of the other? Children can understand } \\
\text { this, right? Or how is the memory imposed in the space? ... But again, this requires you to leave } \\
\text { school.... Or why isn't there a female figure in a statue? They should wonder ... observe ... }\end{array}$ \\
\hline
\end{tabular}


search. Search here, did you see a female figure? No, there is no female figure or I think there is one now, recently put. You can do such things.

\section{In Science Education}

"Hands-on"

experiencing

IBL is seen more as hands-on activities, such as conducting experiments or making observations in order to obtain the expected right results (or prove an already known theory) and understand a natural phenomenon.

"Minds-on"

experiencing

IBL is seen more as minds-on activities, such as conducting experiments, making observations and/or searching in the literature in order to explain a natural phenomenon and become familiar with the scientific way of thinking.

Investigating

IBL is seen more as an active process which resembles problem solving, by generating questions/hypotheses, using methods and tools, conducting

experiments, making observations and/or searching in the literature, analysing information, and formulating arguments; in order to explain a natural phenomenon and eventually learn how to proceed in order to answer their own questions.
1, 2, 7, 13, Teacher 7: Last time we went to a chemistry laboratory and the chemist showed us various 14, 15 chemical reactions of the elements, they were very happy and they really liked it when the colour changed; the alcohol for example, if we throw it in a chemical compound, or if it gets more intense colours. She showed them various such tricks and they really liked them and then, we did them and said them in the classroom. ... Inquiry is all these experiments we try to do.

$4,5,6,8,9$, Teacher 4 : We try to make young scientists in the sense that we try to instil in children the 10,12 logic that in order to come to some conclusions about what is happening around me, first, I should observe something, to pique my interest, and beyond that to do an experiment to see, is this really the case? And then to come to a conclusion, which I will generalise, that since it applies here, it also applies in some other areas. ... We should suspect children, from an early age, in such a way of thinking that... everything around us should have a logical explanation and be based on some, some evidence.

3, $11 \quad$ Teacher 3: Always, in every lesson, I attempt to learn students' prior knowledge, their concerns, what they would like to learn, what would be of their best interest, their perception of the problems that they pose, how it may have been created, and then, through the existing experiments or their opinion [I attempt] to include them in the lesson. ... In science lessons, they should have the willingness to discover ... to search, experimenting with different materials ... to be involved in the natural world and ... to be able even to reconsider some of their opinions and understand that what we often accept as empirical knowledge may not be true and may not be confirmed by scientific knowledge. To be able to come into a conflict with the data they have in mind. ... [In IBL] students, through their questions, through their willingness to discover, either by finding the appropriate tools or by providing them with the appropriate tools, attempt to form hypotheses, and through experimentation to confirm these hypotheses. 


\section{Results}

The results of this study are presented in three sections. The first one gives an overview of teachers' epistemic beliefs which emerged while they were dealing with two controversial topics in history and science. Then, the second section describes teachers' conceptions of IBL both in history and science education. A comparison of teachers' epistemic beliefs and conceptions of IBL between history and science (as groups of patterns or categories and intra-individually) is included. Finally, the third section attempts to capture the interplay of teachers' epistemic beliefs with their conceptions of IBL within each topic and domain, by presenting three illustrative teacher cases.

\subsection{Primary school teachers' epistemic beliefs}

Table 3 includes representative examples of coding teachers' utterances regarding each dimension and perspective of their topic-specific epistemic beliefs. Every participant contributed uniquely to this study by expressing their epistemic beliefs; however, it was possible to detect some patterns in their responses. What follows is a short description of participants' epistemic belief patterns found within the context of the two controversial topics.

\subsubsection{Topic-specific epistemic beliefs in history}

While dealing with the historical topic of the governance of Ioannis Kapodistrias, most participants articulated a complex set of epistemic beliefs without fitting in one single perspective. Their responses revealed some meaningful patterns (see Table 5). Usually, participants' beliefs about the certainty and structure of knowledge fell into the same perspective while their beliefs about the source of knowledge and the justification of knowing were rather complementary. Specifically, a lot of participants were coded as evaluativists regarding the nature of knowledge about this topic, and as multiplists regarding the nature of knowing, especially the justification of knowing. This finding indicates that even though teachers recognised a rather uncertain and interpretive nature of historical knowledge, and were willing to involve themselves in an active process of knowing, they were not familiar with the epistemic criteria necessary to evaluate different sources. On the other hand, some participants were coded as absolutists regarding the nature of historical knowledge and as multiplists and/or evaluativists regarding the nature of knowing. This finding could indicate a more dogmatic view of historical knowledge as certain and mainly based on concrete data, in combination with teachers' willingness to form their own opinion by integrating multiple sources, mainly based, however, on their personal preferences. Furthermore, a few participants can be seen as typical examples of each perspective in total.

\subsubsection{Topic-specific epistemic beliefs in science}

While dealing with the scientific topic, that is the orientation of the migratory birds based on Earth's magnetic field, most participants expressed a rather complex set of epistemic beliefs without fitting into a single perspective. Some meaningful patterns were also detected in participants' responses; however, they were not identical to those found in the historical topic (see Table 5). Quite often, participants' beliefs about the certainty and structure of knowledge fell into the same perspective, and their beliefs about the source of knowledge and the justification of knowing were complementary. Specifically, a lot of participants were coded as evaluativists regarding the nature of knowledge, but also as absolutists regarding the nature of knowing (or even as multiplists for the justification of knowing). This finding could indicate that teachers were familiar with the evolving and interpretive nature of scientific knowledge; but at the same time, they believed that such topics are very specialised for them to have any involvement and make any decision. Besides, if they had to take a perspective, the most common criterion would be what makes sense based on their prior knowledge of the topic and/or logic. A few participants showed a similar pattern with a notable difference regarding their beliefs about the source of knowledge, given that they were coded as evaluativists; but simultaneously, they had difficulty 
articulating specific epistemic criteria for evaluating different sources. Compared with the historical topic, more participants can be seen as typical examples of the absolutist and evaluativist perspectives; but none of the multiplist perspective.

\subsubsection{Intraindividual comparison of teachers' topic-specific epistemic beliefs in history and science}

One third of the participants showed quite similar patterns in their topic-specific epistemic beliefs in history and science. The remaining participants appeared to have more availing epistemic beliefs about the historical topic rather than the scientific one, except for one participant who had the opposite difference (see Table 5).

Table 5

The interplay of teachers' topic-specific epistemic beliefs and their conceptions of IBL in history and science

\begin{tabular}{|c|c|c|c|c|c|c|}
\hline \multirow[b]{2}{*}{ Participant } & \multirow[b]{2}{*}{ Topic } & \multicolumn{4}{|c|}{ Topic-specific Epistemic Belief Patterns } & \multirow[b]{2}{*}{ Conceptions of IBL } \\
\hline & & Certainty & Structure & Source & Justification & \\
\hline \multirow[t]{2}{*}{ Teacher 1} & I. Kapodistrias & $\mathrm{M}$ & $\mathrm{M}$ & $\mathrm{E}$ & $\bar{M}$ & evaluating \\
\hline & Migratory birds & A & A & A & M & "hands-on" experiencing \\
\hline \multirow[t]{2}{*}{ Teacher 2} & I. Kapodistrias & A & A & A & A & understanding \\
\hline & Migratory birds & A & A & A & A & "hands-on" experiencing \\
\hline \multirow[t]{2}{*}{ Teacher 3} & I. Kapodistrias & $\mathrm{E}$ & A & A & E & evaluating \\
\hline & Migratory birds & $\mathrm{E}$ & $\mathrm{E}$ & A & M & investigating \\
\hline \multirow[t]{2}{*}{ Teacher 4} & I. Kapodistrias & $\mathrm{E}$ & $\mathrm{E}$ & $\mathrm{E}$ & M & evaluating \\
\hline & Migratory birds & E & E & A & A & "minds-on" experiencing \\
\hline \multirow[t]{2}{*}{ Teacher 5} & I. Kapodistrias & M & E & $\mathrm{E}$ & M & evaluating \\
\hline & Migratory birds & $\mathrm{E}$ & $\mathrm{E}$ & $\mathrm{E}$ & $\mathrm{M}$ & "minds-on" experiencing \\
\hline \multirow[t]{2}{*}{ Teacher 6} & I. Kapodistrias & $\mathrm{E}$ & E & $M \& E$ & M & investigating \\
\hline & Migratory birds & $\mathrm{E}$ & E & M & M & "minds-on" experiencing \\
\hline \multirow[t]{2}{*}{ Teacher 7} & I. Kapodistrias & A & A & $\mathrm{E}$ & M & evaluating \\
\hline & Migratory birds & A & A & A & A & "hands-on" experiencing \\
\hline \multirow[t]{2}{*}{ Teacher 8} & I. Kapodistrias & $\mathrm{E}$ & E & $\mathrm{E}$ & M & investigating \\
\hline & Migratory birds & $\mathrm{E}$ & $\mathrm{E}$ & $A \& E$ & $A \& E$ & "minds-on" experiencing \\
\hline \multirow[t]{2}{*}{ Teacher 9} & I. Kapodistrias & M & E & $\mathrm{E}$ & M & evaluating \\
\hline & Migratory birds & $\mathrm{E}$ & $\mathrm{E}$ & A & $\mathrm{M}$ & "minds-on" experiencing \\
\hline \multirow[t]{2}{*}{ Teacher 10} & I. Kapodistrias & $\mathrm{E}$ & $\mathrm{E}$ & M & $\mathrm{M}$ & understanding \\
\hline & Migratory birds & $\mathrm{E}$ & A & A & M & "minds-on" experiencing \\
\hline \multirow[t]{2}{*}{ Teacher 11} & I. Kapodistrias & $\mathrm{E}$ & $\mathrm{E}$ & $\mathrm{E}$ & $\mathrm{E}$ & investigating \\
\hline & Migratory birds & $\mathrm{E}$ & $\mathrm{E}$ & $\mathrm{E}$ & $\mathrm{E}$ & investigating \\
\hline \multirow[t]{2}{*}{ Teacher 12} & I. Kapodistrias & $\mathrm{E}$ & $\mathrm{E}$ & $\mathrm{M}$ & $\mathrm{M}$ & investigating \\
\hline & Migratory birds & M & $\mathrm{A} \& \mathrm{E}$ & $\mathrm{A}$ & M & "minds-on" experiencing \\
\hline \multirow[t]{2}{*}{ Teacher 13} & I. Kapodistrias & M & $\mathrm{E}$ & A & $\mathrm{A}$ & understanding \\
\hline & Migratory birds & A & A & A & A & "hands-on" experiencing \\
\hline \multirow[t]{2}{*}{ Teacher 14} & I. Kapodistrias & A & $\mathrm{E}$ & M & $\mathrm{M}$ & investigating \\
\hline & Migratory birds & A & A & $\mathrm{A}$ & $\mathrm{A}$ & "hands-on" experiencing \\
\hline \multirow{2}{*}{ Teacher 15} & I. Kapodistrias & $\mathrm{A}$ & A & A & $\mathrm{A}$ & understanding \\
\hline & Migratory birds & $\mathrm{M}$ & $\mathrm{E}$ & $\mathrm{A}$ & $\mathrm{M}$ & "hands-on" experiencing \\
\hline
\end{tabular}

Notes. A = Absolutism; $\mathrm{M}=$ Multiplism; $\mathrm{E}=$ Evaluativism.

\subsection{Primary school teachers' conceptions of IBL}

\subsubsection{Conceptions of IBL in history education}

Based on the categorisation proposed by Voet and De Wever (2016) and participants' interview responses, three qualitatively different ways of conceptualising IBL in history education were identified: 
understanding, evaluating, and investigating. Table 4 presents these three categories by providing excerpts from teachers' interviews as representative examples of each category. Also, a list of participants in each category is included.

Initially, teachers of the understanding category tended to describe IBL mostly as a practical way of searching and collecting information from additional sources regarding the lesson topic, besides school books. The main goal of IBL is the enhancement of students' content knowledge and a more practical understanding of the lesson. Some teachers mentioned that they should search and collect additional sources to provide students with understandable and simplified information while others described this process by giving to students a more active role. In addition, a few teachers said that critical thinking should be another goal reached through IBL without, however, elaborating further.

The teachers of the evaluating category described IBL mostly as a critical way of learning how to search, compare and evaluate different opinions and potentially conflicting information from different sources about the same topic. The main goal of IBL is the development of a more critical way of thinking and the realisation that history always involves subjectivity. Students' active role was frequently supported by these teachers and some of them further implied that through such a process, students would learn how to discern right and wrong information or even choose the right source, in an attempt to form their own opinions. Many of these teachers hinted at the importance of using trustworthy sources within the context of IBL.

Finally, the teachers of the investigating category described IBL as an active process of generating questions, searching in the literature (or through outdoor activities), collecting and analysing information to form arguments and explain a historical event or phenomenon, which resembles a lot the process of solving a problem by asking research questions. Despite the central role of asking questions in this category, it is worth mentioning that most teachers referred to it more indirectly by formulating questions independently, while giving examples of historical topics. The main goal of IBL for students is to learn how to investigate historical events and phenomena on their own and construct knowledge by integrating information from different sources. Besides, only one teacher highlighted the importance of learning how to argue based on multiple sources, as part of the IBL. Hence, it is apparent that there were some qualitative differences among teachers' conceptions in this category.

\subsubsection{Conceptions of IBL in science education}

Based on the existing literature (Ireland et al., 2012; Voet \& De Wever, 2016) and participants' interview responses, three qualitatively different ways of conceptualising IBL in science education were also detected: "hands-on" experiencing, "minds-on" experiencing, and investigating. Table 4 describes in detail these three categories and presents excerpts from teachers' interviews as representative examples of each category. A list of participants in each category is also included.

Firstly, the teachers of the "hands-on" experiencing category defined IBL mostly as sensory activities, including experiments and/or observations. According to their descriptions, experiments are conducted either by the teacher as a demonstration or by students under the teacher's close supervision in order to find out the expected results and understand the natural phenomena described in their school book more practically. In other words, experimental procedures are used to prove what is already known and has been discovered by scientists. Even though science equipment and materials are described as an integral part of the inquiry, the use of simulations could be an alternative means, when an experiment is difficult to be conducted. However, none referred to the use of the literature without being asked directly by the researcher. Even then, most teachers referred to the literature as necessary information to be learnt or even the theory that students should know before experimenting. Only two teachers replied that searching in the literature for more information could be another kind of inquiry, aiming at understanding (in accordance with the understanding category of IBL in history education), but also mentioned how that would be much less interesting than experiments.

The teachers of the "minds-on" experiencing category also defined IBL as sensory activities, such as experiments and/or observations, aiming furthermore to acquire a more scientific way of thinking, 
while attempting to explain the natural phenomena. Based on their descriptions, students should have a very active role since they are supported by their teacher to search and discover how "nature works" from a scientific point of view. However, the mere experience of experimenting is not enough to describe IBL. The use of simulations was also mentioned as an alternative option. In comparison with the previous category, the teachers of this category have also connected IBL with the experiments and observations rather than with the literature. However, after being asked, most of them supported the idea of searching and using multiple sources as a different kind of inquiry to explain a natural phenomenon, although it is not considered so tempting for students. Only one teacher further connected IBL with the search of the literature in an attempt to compare and contrast multiple sources and their trustworthiness based on critical thinking. This description can be seen as similar to the evaluating category of the IBL in history education.

The teachers of the investigating category were only two and defined IBL more as an active process that resembles the process of solving a problem in order to explain a natural phenomenon, by highlighting the importance of forming hypotheses and/or asking questions. According to their descriptions, students should be very active in the process of inquiry by forming hypotheses; making observations and/or conducting experiments; analysing information to test the hypotheses; and finally, formulating explanations based on evidence. Eventually, the goal for students should be to learn how to proceed in order to ask and answer their questions through inquiry. However, argumentation was not mentioned as part of the IBL. In accordance with the two previous categories, teachers also connected IBL with more material-based activities than with the searching in the literature, and further mentioned the alternative use of simulations. After being asked, the description of one teacher was very close to the investigating category of the IBL in history education, as another kind of inquiry in science education. The importance of learning how to think critically and more scientifically through IBL was also highlighted by both teachers.

\subsubsection{Intraindividual comparison of teachers' conceptions of IBL in history and science education}

Roughly half the participants fell into the same category regarding their conceptions of IBL in both domains, though the recognised categories in history education are not identical with those in science education. The other half of participants appeared to define IBL in history education more thoroughly than IBL in science education, except for two participants who had the opposite difference (see Table 5).

\subsection{The interplay between teachers' epistemic beliefs and their conceptions of IBL}

Unravelling the interplay between teachers' epistemic beliefs and their conceptions of IBL within each topic and domain was the most challenging and essential part of this study. Table 5 gives an overview of participants' epistemic belief patterns for each topic and of their conceptions of IBL within the corresponding domain. There is an interesting interplay between the two constructs.

Starting with history, most participants who described IBL as understanding also expressed absolutist epistemic beliefs, either for all four dimensions (teachers 2 and 15) or at least for that of the nature of knowing (teacher 13). Furthermore, participants who described IBL as evaluating showed a wide range of epistemic belief patterns, but two interesting tendencies were detected: a) almost all of them expressed evaluativist epistemic beliefs about the source of knowledge and multiplist epistemic beliefs about the justification of knowing (teachers 1, 4, 5, 7, and 9); and b) some of them similarly expressed multiplist epistemic beliefs about the certainty of knowledge (teachers 1, 5, and 9). Finally, most participants who described IBL as investigating expressed evaluativist epistemic beliefs, at least regarding the nature and source of knowledge (teachers 6,8 and 11). However, there were participants who could be seen as exceptions in terms of the aforementioned tendencies (e.g., teachers 3,10 and 14).

Continuing with science, roughly all participants who defined IBL in science education as "handson" experiencing expressed absolutist epistemic beliefs (teachers 1, 2, 7, 13 and 14). Furthermore, participants who defined IBL as "minds-on" experiencing also showed a range of epistemic belief 
patterns, but with a common tendency of expressing evaluativist beliefs about the nature of knowledge (teachers 4, 5, 6, 8 and 9). Additionally, some of them were also coded as absolutists about the source of knowledge and/or as multiplists about the justification of knowing (teachers 4, 8, and 9). Finally, the two participants who defined IBL as investigating articulated evaluativist beliefs about the nature of knowledge, but differed in their beliefs about the nature of knowing: one was quite hesitant to involve himself in an active process of knowing (teacher 3), and the other was entirely coded as evaluativist (teacher 11). Nevertheless, there were participants who could be seen as rather exceptions in terms of the aforementioned tendencies (e.g., teachers 3 and 15).

In order to further understand the interplay between teachers' epistemic beliefs and conceptions of IBL, below follows an in-depth analysis of three teacher cases that could represent the aforementioned findings. At the same time, there was an attempt to choose the most illustrative teacher cases of each category of IBL in both history and science education, and also to present the same teacher cases for both domains as a whole in order to make cross-topic and cross-domain comparisons. According to Table 1, letter codes in parentheses follow teachers' quotations to indicate the specific dimension and perspective of their epistemic beliefs. Participants addressed the topics in the same order that they are presented below.

\subsubsection{Teacher 1: IBL as "hands-on" experiencing in science and evaluating in history}

Teacher 1 was 51 years old and he had been teaching at primary schools for 21 years, more than half of them were in the $6^{\text {th }}$ grade. He had completed his 4 -year bachelor studies in primary education, but he had no research experience.

His interview started with the scientific topic and his first reaction was that "I am thinking that yet, there is nothing certain, it hasn't been proven. Although I converge more on the second study" by further explaining that he had read a lot about birds and had first-hand experience. His answers implied that knowledge comes from outside, including studying the bibliography and having first-hand experience by observing the world (Sour*A). Although initially, he seemed unwilling to further justify his way of knowing, as something given, later he explained that he would choose a study based on his personal preferences:

I would read, I would look to see who these researchers are, what everyone has been dealing with, the bibliography they have read, and I would read it too, I would see afterwards, subjectively of course, with which of the two ... I would go. (Just*M)

Following his line of thought, he was asked about the certainty of knowledge regarding the topic to which he noted: "Yes, I believe that in the future, with appropriate experiments and ... observations, [it] can be proven. ... In the future ... [experts] will be able to know." (Cert*A) Besides, he struggled to understand the questions about the structure of knowledge. In fact, he insisted that knowledge consists of "the bibliography and the studies that researchers have done" (Stru*A), even after giving him the option of choosing among data, opinions or interpretations of data as basic components of knowledge.

Afterwards, he exemplified the use of experiments as the most important part of school science, which brings this subject very close to scientific research, even if in a simplified way. Although he repeatedly mentioned the importance of supporting students to discover knowledge instead of transferring it, his description of inquiry in the class was exclusively focused on hands-on activities in order for students to prove what is already known by the scientists: "Inquiry is through the experiments, you give them the materials, you tell them how, what they should do and they see themselves the result ... from what they do, with the instructions." ("hands-on" experiencing)

Then, the interview focused on the historical topic, immediately provoking a more active role, thus indicating a common trend set by participants who appeared to feel more comfortable with the historical topic than with the scientific one. Obviously, he had already developed an opinion about the topic based on many different (written and oral) sources, but the element of subjectivity in history was expressed at every opportunity, without articulating specific criteria for addressing it, except his personal opinion: 
As for Kapodistrias, look, if you ask me now to tell you my opinion about Kapodistrias ... I will speak to you subjectively. I may agree with ... some of what they say here, and with some [I may] disagree. ... I didn't like some of them there, because I have a different perception, right? The sources, when they refer to a historical event, you can't ignore them, right? But you can judge them ... set parameters. ... I have read about Kapodistrias, you have done that at school ... until you became 20 years old, you had a perception. Then, various studies come out and they tell you other things. What you knew based on what you are learning, I believe, it's what shapes you and somewhere you draw a conclusion. (Sour*E, Just*M)

Regarding the nature of knowledge about this topic, his descriptions were indicative of the perspective of multiplism, though he distinguished between the certainty of facts and historians' interpretations of Kapodistrias' ideology:

For his work, whatever he has done, that is, what is mentioned [such as] schools, I do think that we know a few things. Now, about how he was ideologically himself, I don't know. ... Because ... the historian who writes also has his own political, social, economic perceptions and writes as he wants. $($ Cert*M)

[Knowledge consists of] sources. You can draw conclusions from people who lived then and may have known him. ... Of course, since you know who wrote them ... [Knowledge comes from] some who have written, who have been concerned, right? Or from people who may have experienced him in person. Let's not forget the [Greek] civil war ... people ... who lived during the civil war and wrote, you will see that one writes differently, the other writes differently, depending on the different political and social beliefs. (Stru*M)

Going to history education, he directly connected what he already revealed about himself with what his students should achieve through this subject: "[Students] should search on their own, see and understand that history shows us specific historical events, but it also hides the subjective element, that everyone writes as they wish." Regarding IBL, he emphasized the active role of students by developing their own opinion and judging what they read, based on trustworthy sources:

[IBL is] literature searching, and from the internet ... but not from random sites ... That is, maybe with my own guidance with some historians' names who are really historians ... [Students should use sources] which are approved and from there on, through discussion, what everyone believes, to express their opinion, and so forth. That is, to become a historian themselves. ... To understand that the historian will also write their opinion in their own way. (evaluating)

In sum, Teacher 1 apparently had different epistemic beliefs about the two topics, which are considered quite representative examples of absolutism in science and multiplism in history. Furthermore, the way he appeared to deal with knowledge within the context of the two topics was also reflected in his conceptions of IBL in science and history education.

\subsubsection{Teacher 12: IBL as "minds-on" experiencing in science and investigating in history}

Teacher 12 was 43 years old and she had been teaching at primary schools for 18 years, after finishing her 4 -year bachelor studies in primary education. She had taught in the $6^{\text {th }}$ grade for three years. In parallel, she had completed her master studies in the same discipline, during which time she had participated in a qualitative research project.

Her interview started with the historical topic and initially, she had some difficulty involving herself in the task by asking questions regarding the historical accounts and whether they were appropriate for that age group. This reaction was quite common among participants, given that they expected to be addressed merely as teachers. After finding her role in this task as a learner, she took a more active role, concluding that "both of them could be equally right or wrong ... depending on who is studying them." When she was asked to describe how she would go about forming her own opinion, she replied in a way indicative of the belief that knowledge is generated from the self: 
Perhaps, I would study ... more sources and texts, and I would have a more complete picture. ... It's like truth, it has many aspects ... one topic can, each of us can see it from many perspectives depending on our knowledge, level of studies, work and family. I think that each of us ... has a lot of perspectives, so [imagine the scenario] where the perspectives of many are collected. (Sour*M)

Complementary, she expressed multiplist beliefs about the justification of knowing by mentioning subjective criteria that she could apply to judge different sources:

I imagine that you study ... you judge and accordingly you come to conclusions. The criteria now of what you think [is] closer to you. Let's say, I see the structure of a text, its vocabulary. Something is ... perhaps more or less understandable. The style of the text, right? That is, you find elements that may be closer to you, more understandable ... I don't know. (Just*M)

Then, she elaborated on her beliefs about the nature of knowledge, indicating the (re)constructionist nature of historical knowledge, based on the existing sources, which may also result in some uncertainty:

Historians [may know] up to a point, I imagine. Because ... we all learn from some sources, right? Which are the traces of the past from which we try to draw the plot of the history ... so there certainly are gaps. In other words, [historians] don't completely know Kapodistrias, either as a person or his work as a whole. (Cert*E, Stru*E)

Regarding the structure of knowledge, she added that it consists of "a set of things ... an integration of different sources, of data, of an integration in general." (Stru*E) However, she struggled to answer the direct question about the organisation of knowledge, in terms of mentioning quality features.

Interestingly, when the interview focused on history education, she was even more willing to share her way of thinking and working with students. Her definition of IBL was very close to IBL as investigating, even though she did not mention straightforwardly the importance of formulating questions about the past:

[IBL] gives the first role to the student, right? To become a researcher, that is, not to hand learning on a plate, your knowledge, tradition ... You give them paths, you guide them and they search and construct knowledge on their own. ... I think that a student learns only when he/she is interested in something. That is yes, I am also interested and want to learn. Hence, IBL opens up the way, in essence ... You give them the motivation to learn what they want to learn. (investigating)

She continued with the scientific topic, which she characterised as much more difficult to understand compared to the historical one. From the start, she stated that she could not judge which account was right and which was wrong, without being asked, rather influenced by the previous topic. Later, she concluded that if she had to make her own decision, she would search "outside" to find what is really the case:

I would definitely look for more information. Because they both seem just as right or wrong. ... I can't say they are wrong because I don't have evidence that they are wrong; or if they are right, of course. I would do my research ... [and] search to see what is really the case. (Sour*A)

Moreover, she struggled to articulate other criteria for evaluating different sources, except for what makes sense based on logic:

I imagine that it will be ... okay, I should be more confident, [and] have more knowledge to be able to say, yes, this seems to be more logical ... more right? I don't know! But I would definitely look for it. I mean, I couldn't, I can't judge now which of the two, let's say. (Sour*A, Just*M)

Apparently, she could not involve herself in a process of meaning-making and she expected to find the right answer in the literature. On the other hand, based on the two accounts, she doubted that there will be an answer for this topic in the future:

If I judge ... here from the two studies on the same type of bird ... we can see a third [study] that tells us something completely different, right? I don't know whether we could come up with one 
opinion that would be considered correct. I imagine that here the same is true as before, that the opinions are more. ... The robin is most expert; if they could tell us, they would tell us! (Cert*M)

About the structure of knowledge, she was coded as both absolutist and evaluativist due to her evasive answers, which could indicate both her difficulty in articulating her beliefs and addressing such a specialised topic:

In order to know things about the robin, you must have studied them ... through information, but also to study them alive as the researchers do here, who experiment... (Stru*A) Okay, I imagine data at first, right? Opinions may now be different and the interpretations. ... I guess that knowledge is based more on something that is proven ... Now, interpretations? But that's how we end up with interpretations, yes. Again, I will say that it is an integration of all this! (Stru*E)

She often noted the similarity of her thoughts with the previous topic, revealing that she addressed knowledge about both topics in similar terms. Continuing with the science education, she set several goals for her students, which are illustrative of IBL as "minds-on" experiencing, by further elaborating when she was asked to define IBL:

I think that children as physics ... they cannot understand even what the subject includes. ... The only thing that [children] can say is ... that we are doing experiments. But okay, there is a lot behind it, which must ... be discovered by children and based on that, they must acquire appropriate skills. [Such as] ... a way of thinking a little different, to understand ... what it is, the so-called natural environment. The basic vocabulary that concerns the natural environment. ... Its scientific ... profile. How all this is connected to the children themselves ...

Okay, whatever we know about our natural world is through experiments, through investigations, right? So, we cannot ignore this information completely from the way children learn. How else will they learn? If they don't investigate ... or experiment? ("minds-on" experiencing)

In sum, Teacher 12 showed a rather complex set of epistemic beliefs while dealing with both topics and in parallel, described IBL in both domains with an emphasis on how crucial it is that students learn to think more scientifically by developing important skills through inquiry. Although she appeared quite aware of how to organise a lesson through IBL, she struggled to involve herself in an active process of knowing for such specialised topics.

\subsubsection{Teacher 11: IBL as investigating in both history and science}

Teacher 11 was 37 years old, and was both a computer science teacher in secondary education and a primary school teacher, with master studies in both disciplines. During his master studies, he had participated in both qualitative and quantitative research projects; and at the same time, he had been teaching computer science for the first 7 years of his teaching career and as a primary school teacher for the last 5 years. He had taught in the $6^{\text {th }}$ grade for one school year.

His interview started with the historical topic and he immediately involved himself in an active process of meaning-making regarding the two historical accounts. When he was asked how he would go about making his decision on the topic, he replied:

We should investigate more sources that present the issue from all sides and then, with critical thinking and emotional distancing, to be able ... to draw conclusions that are as much as possible... objective and based on sources. But everything has to be ... investigated, somehow. (Sour*E)

When he was asked to mention specific criteria that he could use when it comes to evaluating multiple sources, he focused mainly on how well-justified they are, based on evidence:

Whether they are justified ... and what is their validity ... For something to be considered valid ... it must be based on sources which have a certain power. And not to ... be a product of someone's imagination or subjectivity in a bad way. (Just*E) 
Focusing on the certainty of knowledge about this topic, he believed that historians should investigate further "by applying specific methodology to clarify, as much as possible, the specific historical period and the specific historical figure", implying the possibility of improving the degree of certainty about the topic:

I think that if there is a fruitful discourse between scientists who have followed certain scientific methods and ... principles, I think that even this opposition and multifaceted consideration of this historical figure ... can lead to useful conclusions, so we can rely on them with a greater percentage of certainty. (Cert*E)

Interestingly, he didn't face any difficulty with the questions about the structure of knowledge; instead, he gave insightful descriptions mentioning both different kinds and quality features of knowledge, revealing the complex nature of this dimension.

Knowledge consists of many components ... some of them are about events, others about the results recorded ... which of course are presented sometimes in different ways ... but the knowledge that has to do with the investigation of the causes, ... due to an event that happened or because political decisions had been made, ... the interpretation of [them] in some way... is very much influenced by the researcher's hypotheses. Then, this part is also knowledge, but perhaps it is a knowledge which 'must be constantly doubted' and ... needs to be renegotiated in order to ... bring it closer to reality. ... The structure of knowledge is complex, dynamic, that is non-static, constantly changing ... (Stru*E)

Additionally, when he was asked about the source of knowledge for those who investigate this topic, he brought out the interpretive nature of historical knowledge:

Knowledge is the result of ... the research method [the historians] have chosen, that is, they choose a research method, they process the data of the past, whatever form they take, and their processing and the correct questions that are asked in the past, have, as a result, the extraction of some ... conclusions, which in my opinion are knowledge. (Stru*E)

Then, the interview focused on history education. Even though he noted many differences between historical inquiry and school history, he articulated interesting goals that students should meet through this subject. These goals strongly reflected his epistemic beliefs. He stated that students "... should develop their critical knowledge and learn to argue based on the sources and historical events with which they come into contact, and be able to find some relevance to their own everyday life." Finally, his definition of IBL was the most illustrative of the investigating category: [IBL] presupposes the active action of the students ... With the teacher's guidance, students ... construct knowledge through inquiry, search for sources, analyse information, answer questions on their own and, synthesize and produce knowledge. (investigating)

The interview continued with the scientific topic. While he was dealing with the two scientific accounts, he noted that "both of them are attempts to interpret a natural phenomenon, and they are in completely opposite directions; ... [researchers] interpret [the phenomenon] in a completely different way; they attempt to attribute orientation to different mechanisms. ... but both with plausible arguments." When he was asked to explain his own way of making a decision, he emphasized the importance of being interested in the topic in order to:

... try to have access to ... scientific data and to ... scientific sources in order to see the conclusions of studies that have been done for the specific issue, let's say, of the orientation, so I would try to make a comparison firstly, an investigation of the conclusions, to have a more ... integrated opinion. (Sour*E)

When he was asked to name specific criteria that he would adopt to evaluate different studies, he implied that he might choose the study which would further convince him, based on its justification:

I would investigate it more, I could ... do an investigation of the bibliography, the research that has

been done around it... based on which one would convince me more, let's say, from what point of 
view they see it ... every researcher. I could try to identify a ... study that focused somewhere ... in order to see what the conclusions of other studies say about it. (Just*E)

Regarding the certainty of knowledge about this topic, he was quite hesitant to give a straightforward answer, but his description implied the evolving nature of knowledge through experts' attempts to interpret this phenomenon to a greater extent (Cert*E). Also, he mentioned quite often the case of the reinterpretation of the given findings in light of new research. About the structure of knowledge, he said that knowledge "consists basically of all the conclusions of ... the studies, of all the findings of the studies, of the analysis of the behaviour that has emerged from the observation of the robins; and perhaps of comparative studies between these findings." Finally, he commented that in correspondence with the historical topic, knowledge "is not simple, it is complex ... dynamic in nature ... changing and can be interpreted in many ways." (Stru*E)

Comparing scientific inquiry and school science, he acknowledged many more commonalities than in history, mainly because of the frequent use of experiments in the classrooms, following how scientists work methodologically. He elaborated further by describing specific goals that students should meet through this subject, based on the approach of IBL:

Students can be motivated to construct knowledge in a safe context, where the teacher's role is guiding. I think it has multiple benefits from many aspects, both concerning the cognitive outcomes and the skills that they develop, collaboration and communication, ... and their familiarisation with the scientific process. And basically, it is knowledge gained by students' actions, ... they discover, investigate, learn to compare, learn to think critically, be reflective and discuss with themselves. (investigating)

In sum, Teacher 11 was the only teacher who clearly articulated evaluativist beliefs while dealing with both topics in history and science, and his conceptions of IBL fell into the category investigating for both domains. Hence, it seems that his epistemic beliefs are reflected in the way he conceives IBL through the goals he sets for his students and the skills he believes they need to acquire in the context of these subjects.

\section{Discussion}

This study aimed to investigate qualitatively, through scenario-based semi-structured interviews, the interplay between primary school teachers' topic-specific epistemic beliefs and their conceptions of IBL in history and science education. Overall, the findings of this study extend prior research from different fields, support the nuanced approach of teachers' epistemic beliefs and the more inductive analysis of teachers' conceptions of IBL; and, further delineate the magnitude of their interplay. A discussion of the key findings of this study follows in light of the existing literature by offering theoretical and empirical implications, the study's limitations, and educational implications.

\subsection{A nuanced approach of epistemic beliefs through an integrative framework}

This study provides evidence about how the complex nature of teachers' epistemic beliefs emerged while dealing with two controversial topics in history and science; and further, acknowledges the importance of applying a nuanced approach to detect unique epistemic belief patterns rather than simply categorising epistemic beliefs as "naïve" or "sophisticated" per dimension (Barzilai \& Weinstock, 2015; Feucht, 2011, 2017; Mason, 2016; Merk et al., 2018). This study contributes to the existing literature by giving voice, for the first time, to primary school teachers to articulate their epistemic beliefs within a task of two very different topics. Additionally, the proposed integrative framework could be seen as a useful tool for further conceptual and empirical research on the construct of epistemic beliefs. 
Specifically, most participants aligned with more than one epistemic perspective with regard to different dimensions while dealing with each topic (Feucht, 2011, 2017); however, they could be included in a predominant perspective (Barzilai \& Weinstock, 2015; King \& Kitchener, 1994). Moreover, there were teacher cases who were included in a single perspective for all dimensions and others who could be in transition between two perspectives (Barzilai \& Weinstock, 2015; Feucht, 2011, 2017; Kuhn Cheney, \& Weinstock, 2000). This study did not aim to strictly categorise participants' epistemic beliefs by giving frequency data; on the contrary, it attempted to give thorough descriptions of teachers' epistemic belief patterns in order to challenge and extend the existing frameworks (Greene $\& \mathrm{Yu}, 2014)$. Hence, a scenario-based approach followed by open-ended questions in the form of semistructured interviews was considered to be the best option to gain full access to teachers' wording and thoughts. Teachers' epistemic beliefs were probed within the context of a task where they were asked to deal with controversial topics (Barzilai \& Weinstock, 2015; VanSledright \& Maggioni, 2016); in an attempt to reduce any possible difficulty in answering more general questions about academic domains (Merk et al., 2018). Similar to Barzilai and Weinstock's (2015) conclusion, however, in many teacher cases, their domain-specific epistemic beliefs emerged and interfered while dealing with the specific topics, verifying that topic- and domain-specific beliefs are not independent (see Merk et al., 2018 for a detailed discussion).

Based on the findings of this study, there are some important remarks about the conceptualisation and operationalisation of this construct that should be made. First, most teachers struggled to understand and answer the direct questions about the structure of knowledge for both topics, and they often asked for further clarification. Second, their responses to these questions were very similar to their responses to questions about the source of experts' knowledge, which they also addressed with some difficulty, although less often. Therefore, it seems that primary school teachers may not be wondering what knowledge is and where it resides in their everyday lives; quite reasonably, they had difficulty understanding these questions and finding the appropriate words to describe their thoughts. A different interpretation of this finding could be that the applied questions failed to adequately capture participants' epistemic beliefs about the structure of knowledge. But there were teacher cases who managed to thoroughly articulate their beliefs (e.g., Teacher 11). Third, some participants discriminated between different kinds of knowledge, especially in history (e.g., the events from their potential causes), highlighting the complex nature of this dimension and the importance of recognising the different kinds of knowledge (e.g., declarative, procedural, and conceptual) in the conceptualisation and assessment of epistemic beliefs, verifying, therefore, Greene and Yu's (2014) conclusions. Fourth, teachers' beliefs about the source of knowledge elicited more indirectly by asking them how they would go about making their own decisions on the topics (King \& Kitchener, 1994), instead of asking them about the source of knowledge for experts who investigate these issues (Barzilai \& Weinstock, 2015). Fifth, teachers' beliefs about the source of knowledge and the justification of knowing were found to be distinct but also complementary dimensions, pertaining more to teachers' beliefs about their involvement in knowledge production and their evaluation of different knowledge claims (Feucht, 2011, 2017) instead of how experts develop and establish knowledge in their fields. Nevertheless, teachers' difficulty in articulating epistemic criteria for evaluating different accounts could be a clear indication of their unfamiliarity with experts' practices. But this is only a speculation that needs to be explored.

\subsection{Primary school teachers' conceptions of IBL in history and science education}

This study offers a comprehensive overview of how primary school teachers may conceive IBL in both history and science education. Actually, this is the first study that explored primary school teachers' conceptions of IBL in history and compared them with their conceptions of IBL in science. Regarding history education, the findings of this study provide clear evidence for the applicability of the categorisation proposed by Voet and De Wever (2016) in their study with secondary history teachers. Primary school teachers' conceptions of IBL in history education fell into the following three categories: understanding, evaluating, and investigating. However, the content of these categories was elaborated based on participants' responses. On the other hand, primary school teachers' conceptions of IBL in 
science education did not exactly follow any categorisation of the existing literature. Based more on participants' descriptions of IBL and less on existing coding schemes (Ireland et al., 2012; Voet \& De Wever, 2016), three categories were also identified, which were named "hands-on" experiencing, "minds-on" experiencing and investigating. Moreover, this study adopted a broader view of IBL in science education by directly asking participants to consider the case of IBL in science as a literature search and to use multiple sources regarding a given topic. Hence, within the above three categories, there were also included teachers' conceptions of IBL in science through this perspective; which were found to resemble a lot the three categories of IBL in history.

A general remark is that even though most participants gave interesting and rich descriptions of IBL in both history and science education, very few teachers defined IBL in terms of doing full historical and scientific inquiries within the classroom. Similar to the existing literature (e.g., Ireland et al., 2012; Kang et al., 2008; Voet \& De Wever, 2016), primary school teachers noted very rarely the importance of engaging their students in formulating research questions and argumentation as part of IBL in both history and science. Nevertheless, this study endeavoured to explore how primary school teachers understand and conceptualise IBL through their own wording, rather than capturing the frequency of these conceptions among the participants. Also, these findings do not indicate whether or not these teachers attempt to foster IBL in their classrooms, even though their school experiences may have affected their descriptions (see Voet \& De Wever, 2016 for a detailed description). Besides, according to Levy et al. (2013, p. 396), "understanding the process of IBL [in] history [and science] is necessary but not sufficient for using it in the classroom".

\subsection{Unravelling the interplay of primary school teachers' epistemic beliefs and conceptions of IBL}

This study contributes uniquely to the existing literature, by providing clear indications that primary school teachers' conceptions of IBL, in history and science education, are aligned well with their epistemic belief patterns per topic. In comparison with Voet and De Wever's (2016) findings, with reference to history education, this study found a greater connection between primary school teachers' epistemic beliefs and their conceptions of IBL, probably due to the much more nuanced approach of teachers' epistemic beliefs. Further, even though comparisons of this study with studies from science education (e.g., Chan, 2011; Lee \& Tsai, 2011; Tsai, 2002; see 2.2. and 2.3. Sections) are difficult to make due to the different theoretical constructs involved, this study provides evidence in support of the common claim that teachers who hold more availing epistemic beliefs, also support more "constructivist approaches"; however, in terms of describing IBL more thoroughly in science education.

Regarding history, there is evidence that teachers who held predominantly absolutist epistemic beliefs defined IBL mainly as understanding; and, teachers who held predominantly evaluativist epistemic beliefs defined IBL mainly as investigating. Besides, the epistemic belief patterns of participants who described IBL as evaluating were much more complex, but all of them held evaluativist beliefs about the source of knowledge and multiplist beliefs about the justification of knowing. Overall, it could be argued that the more availing the teachers' epistemic beliefs, the more thoroughly they conceive IBL in history education. In regards to the evaluating category of IBL, it seems that teachers who maintain an active role in the process of knowing, support corresponding goals for their students in history by focusing on evaluating sources and developing critical thinking skills, even though they adopt subjective epistemic criteria. Some teachers of this category maintained a more dogmatic view about the nature of historical knowledge (i.e., it should exclusively consist of data/facts). The latter could be seen as an indication of the greater connection between teachers' beliefs about the nature of knowing and their conceptions of IBL in history. But this hypothesis needs to be further examined.

Regarding science, there is evidence that teachers who held predominantly absolutist epistemic beliefs, defined IBL as "hands-on" experiencing. However, teachers who held predominantly evaluativist epistemic beliefs defined IBL either as "minds-on" experiencing or investigating. Furthermore, the epistemic belief patterns of participants who defined IBL as "minds-on" experiencing were much more complex, with a common tendency to express evaluativist beliefs about the nature of 
knowledge, almost in all cases. Similarly, many of these teachers held absolutist beliefs about the source of knowledge and multiplist beliefs about the justification of knowing. Overall, it could be argued that the more availing the teachers' epistemic beliefs, the more thoroughly they conceive IBL in science education. However, in the "minds-on" experiencing category, the situation is rather more complex and different. Almost all these teachers endorsed the evolving and complex nature of scientific knowledge. However, they mainly described themselves as passive receivers of such specialised knowledge, without articulating other epistemic criteria except for what makes sense based on their prior experiences with magnets. This finding is very interesting because even though these teachers struggled to involve themselves in the process of knowing, they were also quite aware of what IBL is in science education. This might be explained by the more frequent use of IBL, both as a term and instructional goal in science rather than in history education, based on Greek primary school textbooks.

In conclusion, this study reveals that there is a complex interplay between: a) how primary school teachers view knowledge and engage themselves as learners in the process of knowing; b) how teachers conceptualise IBL in order to engage their students in the process of knowing. Additionally, this interplay seems to differ in history and science, but further research is needed to verify these early findings. Also, it could be argued that there is a theoretical overlap between the two constructs (i.e., epistemic beliefs and conceptions of IBL) given that inquiry is a way of knowing and, consequently, teachers' conceptions of IBL could be also addressed as an epistemic construct. Even though this is certainly a foundation for further research, the findings of this study provide ample evidence of the need to separately measure teachers' epistemic beliefs as learners and their conceptions of IBL as teachers; in order to capture in-depth teachers' internal factors that might motivate or prevent them from engaging their students in IBL.

\subsection{Limitations}

Several limitations follow this qualitative study and should be mentioned. First, the results of this study cannot be generalised beyond its context and they should be interpreted with caution, due to its sampling method. Therefore, further research is needed to replicate the usefulness of the integrative framework of epistemic beliefs and the coding frameworks of teachers' conceptions of IBL. Additionally, more research is needed to learn the frequency of the epistemic belief patterns and teachers' conceptions of IBL found in the broader population of primary school teachers. Second, the rather small sample size in terms of statistical analysis and the exploratory nature of this study did not allow for an examination of the nature of this interplay. Thus, future studies could investigate whether this is a causal relationship and further, its potential predictive utility regarding teachers' decisions and practices in terms of IBL. Third, teachers' epistemic beliefs were explored within two specific topics from history and science; hence, research with additional topics is required to verify and extend these results. Fourth, even though this study aimed to elicit teachers' epistemic beliefs and conceptions of IBL and not their practices, the exclusive use of interviews, even in the context of a task, could raise some reasonable criticism regarding the need for triangulation in both data collection and analysis. Future studies could apply additional techniques, such as observations of teachers' classroom behaviours and/or member checking.

\subsection{Educational implications}

The findings of this study raise some important implications for both teacher educators and educational policymakers in Greece concerning both pre- and in-service primary school teachers, and on an international level, by taking into account the different cultural environments. Even though this study does not reflect the proportion of Greek primary school teachers who fit in the aforementioned epistemic belief patterns and conceptions of IBL, it is somehow worrisome that a very small number of the participants: a) expressed predominantly evaluativist epistemic beliefs; and, b) described IBL, comprehensively. Reflecting on these findings, the following crucial question emerged: If one of the 
main aims of contemporary primary education is to engage students in experts' epistemic practices from different domains, in order to learn how to make informed decisions in such an epistemically challenging society, then, how can we best prepare teachers to engage their students in IBL within and across such different subjects as history and science?

Starting with the education of pre-service primary school teachers, it is crucial that they get acquainted with the epistemology underlying different academic domains such as literacy, mathematics, history and science; and furthermore, to get involved in different ways of knowing within and across the corresponding school subjects. Therefore, teacher education programmes should take care of including such crucial elements, both explicitly through the content of the courses provided, and implicitly through teacher educators' practices (Greene \& Yu, 2016; Guilfoyle et al., 2020; Voet \& De Wever, 2016; Sinatra \& Hofer, 2016). Within such educational contexts, pre-service teachers can be triggered to reflect on their epistemic beliefs and conceptions of IBL, and their interconnections (Fives et al., 2015), and acquire determining experiences of planning and implementing IBL in action (Ireland et al., 2012; Levy et al., 2013; Martell, 2020). At the same time, in-service teachers should be supported in similar ways through their participation in professional development programmes, after having taken further care of their more established beliefs and conceptions, due to their long teaching experience (Fives \& Buehl, 2012, 2016). The recent conceptual work on teachers' epistemic cognition in action while learning to teach, and in teaching action, incorporates many of the elements mentioned above (e.g., Buehl \& Fives, 2016; Feucht et al., 2017; Hagani \& Barzilai, 2018; Lunn Brownlee et al., 2017).

\section{Footnote:}

1. Although the interchangeable use of the terms "belief" and "conception" is quite often found in such a large and interdisciplinary research field as teachers' beliefs, followed by conceptual issues and measurement limitations, the present study: a) used these terms in the theoretical background based on the cited literature each time; and, b) adopted the term "conception" to approach how primary school teachers conceive IBL in history and science education based on the existing literature (Ireland et al., 2012; Voet \& De Wever, 2016).

\section{Acknowledgments:}

The authors would like to thank Lida Desikou for acting as a critical reader of this manuscript and for her assistance in transcribing the interview data. This research was financially supported by the General Secretariat for Research and Technology (GSRT) and the Hellenic Foundation for Research and Innovation (HFRI) under the HFRI PhD Fellowship grant (Fellowship Number: 231) allocated to the first author.

\section{Keypoints}

- Based on an integrative framework, a nuanced qualitative approach of teachers' epistemic beliefs was applied.

- Primary school teachers' epistemic beliefs were elicited while they were dealing with controversial topics both in history and science.

- Important domain differences were detected in primary school teachers' conceptions of inquiry-based learning.

- Primary school teachers' epistemic beliefs and conceptions of inquiry-based learning are interconnected in both history and science. 


\section{References}

Avraamidou, L. (2017). A well-started beginning elementary teacher's beliefs and practices in relation to reform recommendations about inquiry-based science. Cultural Studies of Science Education, 12(2), 331-353. doi: 10.1007/s11422-015-9700-x

Bartos, S. A., \& Lederman, N. G. (2014). Teachers' knowledge structures for nature of science and scientific inquiry: Conceptions and classroom practice. Journal of Research in Science Teaching, 51(9), 1150-1184. doi: 10.1002/tea.21168

Barzilai, S., \& Weinstock, M. (2015). Measuring epistemic thinking within and across topics: A scenario-based approach. Contemporary Educational Psychology, 42, 141-158. doi: 10.1016/j.cedpsych.2015.06.006

Bendixen, L., Winsor, D. Frazier, R. (2017). Exploring Bloom's taxonomy as a bridge to evaluativism: Conceptual clarity and implications for learning, teaching, and assessing. In G. Schraw, J. Lunn Brownlee, L. Olafson and M. Vanderveldt (Eds.), Teachers' personal epistemologies: Evolving models for informing practice (pp. 191-211). Charlotte, NC: Information Age Publishing.

Buehl, M. M., \& Beck, J. S. (2015). The relationship between teachers' beliefs and teachers' practices. In H. Fives \& M. G. Gill (Eds.), International handbook of research on teachers' beliefs (pp. 66-84). New York, NY: Routledge.

Buehl, M. M., \& Fives, H. (2009). Exploring teachers' beliefs about teaching knowledge: Where does it come from? Does it change? The Journal of Experimental Education, 77(4), 367-408. doi: 10.3200/JEXE.77.4.367-408

Buehl, M. M., \& Fives, H. (2016). The role of epistemic cognition in teacher learning and praxis. In J. A. Greene, W. A. Sandoval, \& I. Bråten (Eds.), Handbook of epistemic cognition (pp. 247-264). New York, NY: Routledge.

Chan, K.-W. (2011). Preservice teacher education students' epistemological beliefs and conceptions about learning. Instructional Science, 39(1), 87-108. doi: 10.1007/s11251-009-9101-1

Cheng, M. M. H., Chan, K.-W., Tang, S. Y. F., \& Cheng, A. Y. N. (2009). Pre-service teacher education students' epistemological beliefs and their conceptions of teaching. Teaching and Teacher Education, 25(2), 319-327. doi: 10.1016/j.tate.2008.09.018

Chi, M. T. H. (1997). Quantifying qualitative analyses of verbal data: A practical guide. Journal of the Learning Sciences, 6(3), 271-315. doi: 10.1207/s15327809jls0603_1

Chinn, C. A., Buckland, L. A., \& Samarapungavan, A. L. A. (2011). Expanding the dimensions of epistemic cognition: Arguments from philosophy and psychology. Educational Psychologist, 46(3), 141-167. doi: 10.1080/00461520.2011.587722

Cohen, L., Manion, L., \& Morrison, K. (2007). Research methods in education (6th ed.). USA: Routledge.

Creswell, J. W. (2015). Educational research: planning, conducting, and evaluating quantitative and qualitative research (5th ed.). Boston: Pearson.

Dobber, M., Zwart, R., Tanis, M., \& van Oers, B. (2017). Literature review: The role of the teacher in inquiry-based education. Educational Research Review, 22, 194-214. doi: 10.1016/j.edurev.2017.09.002

European Commission. (2015). Science education for responsible citizenship. Brussels: DirectorateGeneral for Research and Innovation, Science with and for Society. http://ec.europa.eu/research/swafs/pdf/pub_science education/KI-NA-26-893-EN-N.pdf

Feucht, F. C. (2011). The epistemic underpinnings of Mrs. M's reading lesson on drawing conclusions: A classroom-based research study. In J. Brownlee, G. Schraw, \& D. Berthelsen (Eds.), Personal epistemology and teacher education (pp. 227-245). New York: Routledge.

Feucht, F. C. (2017). The epistemic climate of Mrs. M's science lesson about the woodlands as an ecosystem: A classroom-based research study. In G. Schraw, J. Lunn Brownlee, L. Olafson and M. Vanderveldt (Eds.), Teachers' personal epistemologies: Evolving models for informing practice (pp. 55-84). Charlotte, NC: Information Age Publishing. 
Feucht, F. C., Lunn Brownlee, J., \& Schraw, G. (2017). Moving beyond reflection: Reflexivity and epistemic cognition in teaching and teacher education. Educational Psychologist, 52(4), 234241. doi: 10.1080/00461520.2017.1350180

Fives, H., \& Buehl, M. M. (2012). Spring cleaning for the "messy" construct of teachers' beliefs: Whay are they? Which have been examined? What can they tell us? In K. Harris, S. Graham, T. Urdan, C. McCormick, G. M. Sinatra, \& J. Sweller (Eds.), APA educational psychology handbook, Vol 2: Individual differences and cultural and contextual factors (pp. 471-499). Washington, DC: American Psychological Association.

Fives, H., \& Buehl, M. M. (2016). Teachers' beliefs, in the context of policy reform. Policy Insights from the Behavioral and Brain Sciences, 3(1), 114-121. doi: 10.1177/2372732215623554

Fives, H., \& Buehl, M. M. (2017). The functions of beliefs: Teachers' personal epistemology on the pinning block. In G. Schraw, J. Lunn Brownlee, L. Olafson and M. Vanderveldt (Eds.), Teachers' personal epistemologies: Evolving models for informing practice (pp. 25-54). Charlotte, NC: Information Age Publishing.

Fives, H., Lacatena, N., \& Gerard, L. (2015). Teachers' beliefs about teaching (and learning). In H. Fives \& M. G. Gill (Eds.), International handbook of research on teachers' beliefs (pp. 249265). New York, NY: Routledge.

Forbes, C. T., Biggers, M., \& Zangori, L. (2013). Investigating essential characteristics of scientific practices in elementary science learning environments: The Practices of Science Observation Protocol (P-SOP). School Science and Mathematics, 113(4), 180-190. doi: 10.1111/ssm. 12014

Gillies, R. M., \& Nichols, K. (2015). How to support primary teachers' implementation of inquiry: teachers' reflections on teaching cooperative inquiry-based science. Research in Science Education, 45(2), 171-191. doi: 10.1007/s11165-014-9418-x

Greene, J. A., Sandoval, W. A., \& Bråten, I. (2016a). An introduction to epistemic cognition. In J. A. Greene, W. A. Sandoval, \& I. Bråten (Eds.), Handbook of epistemic cognition (pp. 1-16). New York, NY: Routledge.

Greene, J. A., Sandoval, W. A., \& Bråten, I. (2016b). Handbook of epistemic cognition. New York, NY: Routledge.

Greene, J. A., Sandoval, W. A., \& Bråten, I. (2016c). Reflections and future directions. In J. A. Greene, W. A. Sandoval, \& I. Bråten (Eds.), Handbook of epistemic cognition (pp. 495-510). New York, NY: Routledge.

Greene, J. A., \& Yu, S. B. (2014). Modeling and measuring epistemic cognition: A qualitative reinvestigation. Contemporary Educational Psychology, 39(1), 12-28. doi: 10.1016/j.cedpsych.2013.10.002

Greene, J. A., \& Yu, S. B. (2016). Educating critical thinkers: The role of epistemic cognition. Policy Insights from the Behavioral and Brain Sciences, 3(1), 45-53. doi: 10.1177/2372732215622223

Greene, J. A., Yu, S. B., \& Copeland, D. Z. (2014). Measuring critical components of digital literacy and their relationships with learning. Computers \& Education, 76, 55-69. doi: 10.1016/j.compedu.2014.03.008

Guilfoyle, L., McCormack, O., \& Erduran, S. (2020). The "tipping point" for educational research: The role of pre-service science teachers' epistemic beliefs in evaluating the professional utility of educational research. Teaching and Teacher Education, 90, 103033. doi: 10.1016/j.tate. 2020.103033

Hagani, S. M. \& Barzilai, S. (2018). Reflecting on epistemic ideals and processes: Designing opportunities for teachers' epistemic growth. In J. Kay, \& R. Luckin (Eds.) Rethinking Learning in the Digital Age: Making the Learning Sciences Count, 13th International Conference of the Learning Sciences (ICLS) 2018, Vol. 2. London, UK: International Society of the Learning Sciences. Retrieved from https://doi.dx.org/10.22318/cscl2018.1129

Hammer, D., \& Elby, A. (2002). On the form of a personal epistemology. In B. K. Hofer \& P. R. Pintrich (Eds.), Personal epistemology: The psychology of beliefs about knowledge and knowing (pp. 169-190). Lawrence Erlbaum Associates, Inc.

Hofer, B. K. (2000). Dimensionality and disciplinary differences in personal epistemology. Contemporary Educational Psychology, 25(4), 378-405. doi: 10.1006/ceps.1999.1026 
Hofer, B. K. (2001). Personal epistemology research: Implications for learning and teaching. Educational Psychology Review, 13(4), 353-383. doi: 10.1023/a:1011965830686

Hofer, B. K. (2016). Epistemic cognition as a psychological construct: Advancements and challenges. In J. A. Greene, W. A. Sandoval, \& I. Bråten (Eds.), Handbook of epistemic cognition (pp. 1938). New York, NY: Routledge.

Hofer, B. K., \& Bendixen, L. D. (2012). Personal epistemology: Theory, research, and future directions. In K. R. Harris, S. Graham, \& T. Urdan (Eds.), APA Educational Psychology Handbook: Theories, Constructs, and Critical Issues (Vol. 1, pp. 227-256). Washington, DC: American Psychological Association.

Hofer, B. K., \& Pintrich, P. R. (1997). The development of epistemological theories: Beliefs about knowledge and knowing and their relation to learning. Review of Educational Research, 67(1), 88-140. doi: 10.3102/00346543067001088

Hofer, B. K., \& Pintrich, P. R. (2002). Personal epistemology: The psychology of beliefs about knowledge and knowing: Lawrence Erlbaum Associates, Inc.

Holland, R. A., \& Helm, B. (2013). A strong magnetic pulse affects the precision of departure direction of naturally migrating adult but not juvenile birds. Journal of the Royal Society Interface, 10(81). doi: $10.1098 /$ rsif.2012.1047

Hsieh, H.-F., \& Shannon, S. E. (2005). Three approaches to qualitative content analysis. Qualitative Health Research, 15(9), 1277-1288. doi: 10.1177/1049732305276687

Ireland, J. E., Watters, J. J., Brownlee, J., \& Lupton, M. (2012). Elementary teacher's conceptions of inquiry teaching: Messages for teacher development. Journal of Science Teacher Education, 23(2), 159-175. doi: 10.1007/s10972-011-9251-2

Kang, N.-H. (2008). Learning to teach science: Personal epistemologies, teaching goals, and practices of teaching. Teaching and Teacher Education, 24(2), 478-498. doi: 10.1016/j.tate.2007.01.002

Kang, N.-H., Orgill, M., \& Crippen, K. J. (2008). Understanding teachers' conceptions of classroom inquiry with a teaching scenario survey instrument. Journal of Science Teacher Education, 19(4), 337-354. doi: 10.1007/s10972-008-9097-4

King, P. M., \& Kitchener, K. S. (1994). Developing reflective judgment: Understanding and promoting intellectual growth and critical thinking in adolescents and adults. San Francisco, California: Jossey-Bass Publishers.

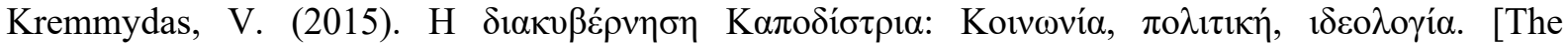

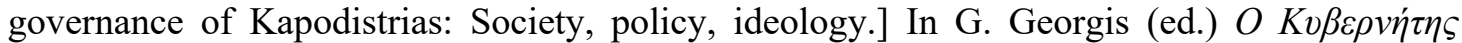

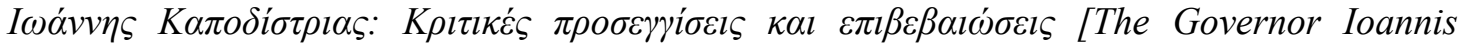
Kapodistrias: Critical approaches and confirmations] (pp. 46-53). Athens: Kastaniotis. [in Greek]

Kuhn, D. (1999). A developmental model of critical thinking. Educational researcher, 28(2), 16-46. Retrieved from www.jstor.org/stable/1177186

Kuhn, D., Cheney, R., \& Weinstock, M. (2000). The development of epistemological understanding. Cognitive Development, 15(3), 309-328. doi: 10.1016/S0885-2014(00)00030-7

Kuhn, D., Iordanou, K., Pease, M., \& Wirkala, C. (2008). Beyond control of variables: What needs to develop to achieve skilled scientific thinking? Cognitive Development, 23(4), 435-451. doi: 10.1016/j.cogdev.2008.09.006

Kuhn, D., \& Weinstock, M. (2002). What is epistemological thinking and why does it matter? In B. K. Hofer \& P. R. Pintrich (Eds.), Personal epistemology: The psychology of beliefs about knowledge and knowing (pp. 121-144). Mahwah, NJ: Erlbaum.

Lakin, J. M., \& Wallace, C. S. (2015). Assessing dimensions of inquiry practice by middle school science teachers engaged in a professional development program. Journal of Science Teacher Education, 26(2), 139-162. doi: 10.1007/s10972-014-9412-1

Lee, M-H., Tsai, C.-C. (2011). Teachers' scientific epistemological views, conceptions of teaching science, and their approaches to teaching science: An exploratory study of in-service science teachers in Taiwan. In J. Brownlee, G. Schraw, \& D. Berthelsen (Eds.), Personal epistemology and teacher education (pp. 246-262). New York: Routledge. 
Levy, B. L. M., Thomas, E. E., Drago, K., \& Rex, L. A. (2013). Examining studies of inquiry-based learning in three fields of education: sparking generative conversation. Journal of Teacher Education, 64(5), 387-408. doi: 10.1177/0022487113496430

Lunn Brownlee, J., Ferguson, L. E., \& Ryan, M. (2017). Changing teachers' epistemic cognition: a new conceptual framework for epistemic reflexivity. Educational Psychologist, 52(4), 242-252. doi: $10.1080 / 00461520.2017 .1333430$

Maggioni, L., VanSledright, B., \& Alexander, P. A. (2009). Walking on the borders: A measure of epistemic cognition in history. The Journal of Experimental Education, 77(3), 187-214. doi: 10.3200/JEXE.77.3.187-214

Martell, C. C. (2020). Barriers to inquiry-based instruction: A longitudinal study of history teachers. Journal of Teacher Education, 71(3), 279-291. doi: 10.1177/0022487119841880

Mason, L. (2016). Psychological perspectives on measuring epistemic cognition. In J. A. Greene, W. A. Sandoval, \& I. Bråten (Eds.), Handbook of epistemic cognition (pp. 375-392). New York, NY: Routledge.

Mayring, P. (2000). Qualitative content analysis. Forum: Qualitative Social Research, 1(2). doi: 10.17169/fqs-1.2.1089

Merk, S., Rosman, T., Muis, K. R., Kelava, A., \& Bohl, T. (2018). Topic specific epistemic beliefs: Extending the Theory of Integrated Domains in Personal Epistemology. Learning and Instruction, 56, 84-97. doi: 10.1016/j.learninstruc.2018.04.008

Merriam, S. B. (2009). Qualitative research: A guide to design and implementation. San Francisco, CA: Jossey-Bass.

Muis, K. R. (2004). Personal epistemology and mathematics: A critical review and synthesis of research. Review of Educational Research, 74(3), 317-377. doi: 10.3102/00346543074003317

Muis, K. R., Bendixen, L. D., \& Haerle, F. C. (2006). Domain-generality and domain-specificity in personal epistemology research: Philosophical and empirical reflections in the development of a theoretical framework. Educational Psychology Review, 18(1), 3-54. doi: 10.1007/s10648006-9003-6

Muis, K. R., \& Foy, M. J. (2010). The effects of teachers' beliefs on elementary students' beliefs, motivation, and achievement in mathematics. In L. D. Bendixen \& F. C. Feucht (Eds.), Personal epistemology in the classroom: Theory, research and implications for practice. New York, NY: Cambridge University Press.

National Council for the Social Studies (NCSS). (2010). National curriculum standards for social studies: A framework for teaching, learning, and assessment (Silver Spring, MD). Retrieved from http://www.socialstudies.org/standards

National Council for the Social Studies (NCSS). (2018). National Standards for the Preparation of Social Studies Teachers. Retrieved from https://www.socialstudies.org/standards/nationalstandards-preparation-social-studies-teachers

Next Generation Science Standards (NGSS) Lead States. (2013). Next Generation Science Standards: For states, by states. Washington, DC: National Academies Press.

National Research Council (NRC). (2012). A Framework for K-12 Science Education: Practices, Crosscutting Concepts, and Core Ideas. Committee on a Conceptual Framework for New K-12 Science Standards. Board on Science Education, Division of Behavioral and Social Sciences and Education. Washington, DC: The National Academies Press.

Olafson, L., \& Schraw, G. (2010). Beyond epistemology: assessing teachers' epistemological and ontological worldviews. In L. D. Bendixen \& F. C. Feucht (Eds.), Personal epistemology in the classroom: Theory, research and implications for practice (pp. 516-551). New York, NY: Cambridge University Press.

Pedaste, M., Mäeots, M., Siiman, L. A., de Jong, T., van Riesen, S. A. N., Kamp, E. T., .. . Tsourlidaki, E. (2015). Phases of inquiry-based learning: Definitions and the inquiry cycle. Educational Research Review, 14, 47-61. doi: 10.1016/j.edurev.2015.02.003

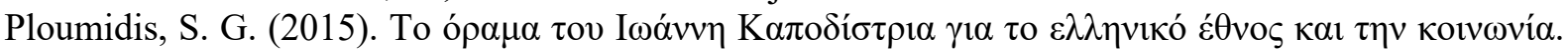
[The vision of Ioannis Kapodistrias for the Greek nation and society.] In G. Georgis (ed.) $O$

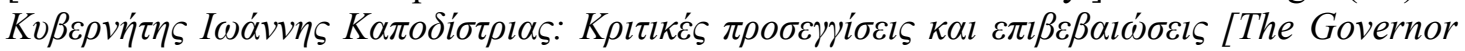


Ioannis Kapodistrias: Critical approaches and confirmations] (pp. 68-87). Athens: Kastaniotis. [in Greek]

Sandoval, W. A. (2005). Understanding students' practical epistemologies and their influence on learning through inquiry. Science Education, 89(4), 634-656. doi: 10.1002/sce.20065

Schraw, G., Lunn Brownlee, J., Olafson, L., \& Vanderveldt, M. (2017). Teachers' personal epistemologies: Evolving models for informing practice. Charlotte, NC: Information Age Publishing.

Seung, E., Park, S., \& Jung, J. (2014). Exploring preservice elementary teachers' understanding of the essential features of inquiry-based science teaching using evidence-based reflection. Research in Science Education, 44(4), 507-529. doi: 10.1007/s11165-013-9390-x

Sinatra, G. M. (2016). Thoughts on knowledge about thinking about knowledge. In J. A. Greene, W. A. Sandoval, \& I. Bråten (Eds.), Handbook of epistemic cognition (pp. 479-491). New York, NY: Routledge.

Sinatra, G. M., \& Hofer, B. K. (2016). Public understanding of science. Policy Insights from the Behavioral and Brain Sciences, 3(2), 245-253. doi: 10.1177/2372732216656870

Tsai, C.-C. (2002). Nested epistemologies: Science teachers' beliefs of teaching, learning and science. International Journal of Science Education, 24(8), 771-783. doi: 10.1080/09500690110049132

Tsai, C.-C. (2007). Teachers' scientific epistemological views: The coherence with instruction and students' views. Science Education, 91(2), 222-243. doi: 10.1002/sce.20175

van Uum, M. S. J., Verhoeff, R. P., \& Peeters, M. (2016). Inquiry-based science education: towards a pedagogical framework for primary school teachers. International Journal of Science Education, 38(3), 450-469. doi: 10.1080/09500693.2016.1147660

VanSledright, B., \& Maggioni, L. (2016). Epistemic cognition in History. In J. A. Greene, W. A. Sandoval, \& I. Bråten (Eds.), Handbook of epistemic cognition (pp. 128-146). New York, NY: Routledge.

Voet, M., \& De Wever, B. (2016). History teachers' conceptions of inquiry-based learning, beliefs about the nature of history, and their relation to the classroom context. Teaching and Teacher Education, 55, 57-67. doi: 10.1016/j.tate.2015.12.008

Wiltschko, R., Gehring, D., Denzau, S., Nießner, C., \& Wiltschko, W. (2014). Magnetoreception in birds: II. Behavioural experiments concerning the cryptochrome cycle. The Journal of Experimental Biology, 217(23), 4225-4228. doi: 10.1242/jeb.110981

Windschitl, M. (2002). Framing constructivism in practice as the negotiation of dilemmas: An analysis of the conceptual, pedagogical, cultural, and political challenges facing teachers. Review of Educational Research, 72(2), 131-175. doi: 10.3102/00346543072002131

Windschitl, M. (2004). Folk theories of "inquiry:" How preservice teachers reproduce the discourse and practices of an atheoretical scientific method. Journal of Research in Science Teaching, 41(5), 481-512. doi: 10.1002/tea.20010 


\section{Appendix A1: Scenarios}

\section{History Scenario (developed based on authentic historical studies)}

\section{The governance of Ioannis Kapodistrias}

The following text developed on the occasion of Chapter 17 of the history textbook of the $6^{\text {th }}$ grade, entitled "Ioannis Kapodistrias and his work" (pp. 138-139), based on the following published secondary sources:

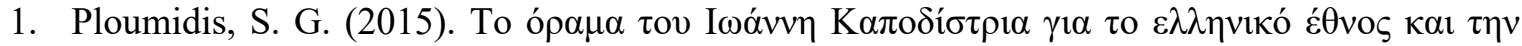

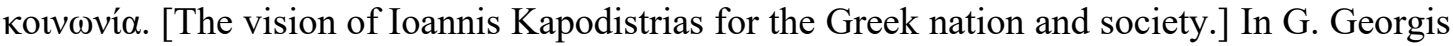

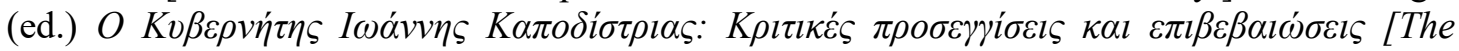
Governor Ioannis Kapodistrias: Critical approaches and confirmations] (pp. 68-87). Athens: Kastaniotis. [in Greek]

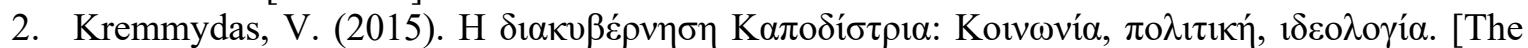
governance of Kapodistrias: Society, policy, ideology.] In G. Georgis (ed.) $O$ Kv $\beta \varepsilon \rho v \dot{\eta} \tau \eta \varsigma$

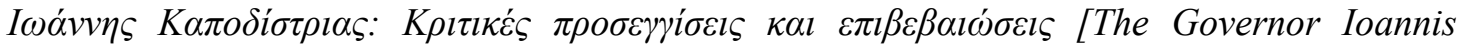
Kapodistrias: Critical approaches and confirmations] (pp. 46-53). Athens: Kastaniotis. [in Greek]

\section{Introduction}

"In 1827, the Third National Assembly of Troizina elected Ioannis Kapodistrias Governor of Greece. Kapodistrias arrived in Nafplio, the first capital of the Greek state, taking over the government of a country that had emerged from a long fight while its inhabitants and especially the refugees were impoverished. The Governor attempted to organise the state, improving its administration and economy. In order to achieve his goal, he concentrated all the authority on his face, postponing for two years the convening of the Fourth National Assembly. [...] The centralist governance of Kapodistrias and his conflict with many local interests provoked the dissatisfaction of political groups that reacted to his policy. On September 27, 1831, Kapodistrias was assassinated in Nafplio, resulting in anarchy in the country." (Excerpt from the Greek textbook of history entitled "History of the modern and contemporary world").

Ioannis Kapodistrias and his work have been the research field for many historians of Modern and Contemporary Greek History. Excerpts from the research work of two Greek historians follow, explaining the governance of Ioannis Kapodistrias.

\section{Account A}

Excerpt from the chapter "The vision of Ioannis Kapodistrias for the Greek nation and society" written by the historian S. G. Ploumidis (2015), Assistant Professor of the National and Kapodistrian University of Athens.

"In the collective consciousness of the Greek people, the myth of Kapodistrias is made around 'BarbaJohn' and all the symbolism and stereotypes that accompany the name of the Father Protector (hence, Mavromichalaioi are presented as patricides); in Kapodistrias, from the time of his arrival in Greece, was given the status of Messiah: the one who, in times of crisis, would undertake to restore trust and ensure the necessary continuity of the national 'family'. ${ }^{1}$ Hence, Kapodistrias' views were not coincidental and fragmentary, but together constituted a comprehensive and structured long-term political programme. Kapodistrias, despite nepotism and an authoritarian way of exercising his governmental power, had a genuine interest in the popular classes, he abhorred client networks and wanted a small state with a minimal number of civil servants. He clearly detested the 'insidious and ambitious who had been brought up in the Muslim school' [of administration] and 'in the school of Fanari of Constantinople', that is, the Kotzabasids, and their 'system' of authority. And he envisioned the 'rebirth of the people' (régénération du peuple) ${ }^{2}$ in a completely different and unconventional way 
'from above', without the alliance of the traditional pre-revolutionary elites: through the creation of a compact class of smallholder farmers and through hard productive labour. So, the basic belief of the Governor was that the people are civilised with hoes and not with bayonets ${ }^{3}$. However, with his harsh adherence to ground-breaking innovation and his pro-popular authoritarianism, he limited himself - we would even say that he self-trapped, in the passive consent of the landless farmers, who did no weigh decisively in the political struggle. ${ }^{4}$ In addition, the first Governor of Greece based his expectations and plans on the long term. His long-term social programme needed a long time to mature. But time was not on his side. The premature and sudden violent death of the Governor has halted the implementation of this long-term and grandiose social vision.” (pp. 86-87)

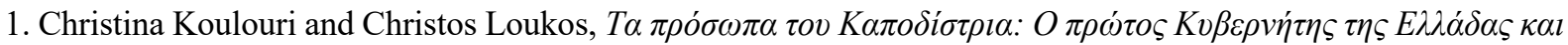

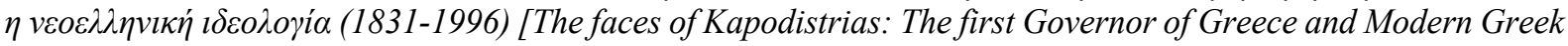
ideology (1831-1996)], Poreia, Athens 1996, p. 28. [in Greek]

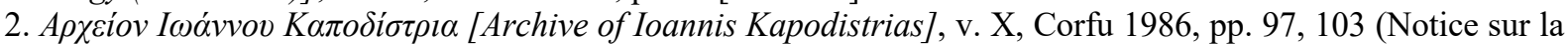
situation de la Grece, November 6/18, 1830). [in Greek]

3. In the same, v. VIII, p. 37; Dimitris Loules, The Financial and Economic Policies of President Ioannis Capodistrias 1828-1831, Ioannina 1985, pp. 111-112.

4. C. M. Woodhouse, Capodistrias: The Founder of Greek Independence, London 1973, p. 431; Loukos, H

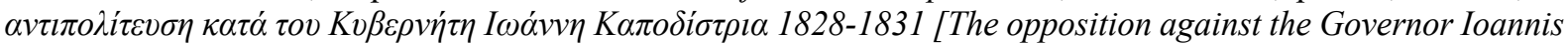
Kapodistrias 1828-1831], Athens 1988, pp. 42, 398. [in Greek]

\section{Account B}

Excerpts from the chapter "The governance of Kapodistrias: Society, policy, ideology" written by the historian V. Kremmydas (2015), Emeritus Professor of the National and Kapodistrian University of Athens.

"From the moment he was informed of his election, Io. Kapodistrias trembled at the idea that he would govern with a Constitution - he was determined not to do so, even if he needed to deny the position of Governor.

But what is the reason for both his specific behaviour and the whole policy?

Io. Kapodistrias was an irreconcilable follower of the socio-political system of the Enlightened Despair and a fan of the policy of the Holy Alliance against the revolutionary movements.

As a political system, the Enlightened Despair was a kind of resistance of totalitarianism to the Enlightenment and implemented the following programme: favour and order; development of agriculture and trade, and basic education, that is, education for the people. But only the enlightened despot knew what would benefit agriculture, trade and the people.

If we pay attention to the actions of the Governor, we will find: first instance courts in each province, primary schools in each province as well, liberation of the seas from piracy to facilitate the trade, sale of cheap income, i.e., land, to farmers to develop agriculture.

Together, frequent tours and contact with the 'people', to show the interest of the 'father', but also for the history to record the return of his 'love' for him - a boundless paternalism, if we want it, in today's terms.

This, however, the loving relationship of the bright father with the small people, as much as it can be characterised as pro-people policy, can equally be [characterised] as anti-social; Ioannis Kapodistrias was not interested in the society and social relations.

Let me now read you a short excerpt, foreign:

'All the care of the Governor was focused on how to exclude the Phanariotes from things and he did not have to put in their position no other but only Iakovakis Rizos, who showed the greatest ingratitude as Phanariot." ${ }^{1}$

[...] The Governor did not want to have any established power in front of him, even if it was with him; because then it would seem as if he was sharing his power with them." (pp. 47-48)

"The end of Kapodistrias governance with his violent end was only the result of a tough conflict at the social, ideological and political level of almost four years; a conflict of power. The end with the 
assassination of the Governor seems like the solution to a drama that was played almost every day." (p. 52)

"Kapodistrias did not clash with local authorities; he despised the social relations, as they had been formed in the vortex of the Revolution. He organised and exerted his policy in the absence of society." (p. 53)

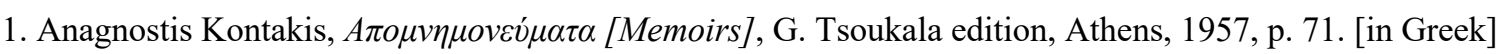

\section{Science Scenario (developed based on authentic scientific studies)}

\section{The orientation of migratory birds based on Earth's magnetic field}

The following text developed on the occasion of the reference of the science textbook of the $6^{\text {th }}$ grade to the migratory birds and how they are oriented themselves based on Earth's magnetic field (thematic unit: electromagnetism, pp. 96-97), based on the following published scientific studies:

1. Holland, R. A., \& Helm, B. (2013). A strong magnetic pulse affects the precision of departure direction of naturally migrating adult but not juvenile birds. Journal of the Royal Society Interface, 10(81). doi: 10.1098/rsif.2012.1047

2. Wiltschko, R., Gehring, D., Denzau, S., Nießner, C., \& Wiltschko, W. (2014). Magnetoreception in birds: II. Behavioural experiments concerning the cryptochrome cycle. The Journal of Experimental Biology, 217(23), 4225-4228. doi: 10.1242/jeb.110981

\section{Introduction}

"Every year, millions of migratory birds travel thousands of miles from one part of the planet to another and when they return, they usually find their old nest again, without anyone showing them the way. This feat of birds has not been fully explained by researchers. It is known, however, that some species of birds, in addition to the position of the Sun, the direction of the wind and the sight, also perceive and use the magnetic field of the Earth for their orientation. That way, they can continue their journey even at night, when they cannot orient themselves visually." (Excerpt from the Greek textbook of science entitled "Primary school science: Investigate and discover").

An example of migratory birds that scientists often study is the European robin (Erithacus Rubecula). Several studies have been conducted to identify possible mechanisms that allow robins to recognise and use the Earth's magnetic field in order to orient themselves and make their journey. A brief description of two scientific studies conducted with European robins follows, explaining the orientation of migratory birds based on Earth's magnetic field.

\section{Account A}

Brief description of the study conducted by the researchers R. A. Holland and B. Helm (2013) of the Max Planck Institute for Ornithology and University of Konstanz in Germany.

Researchers claim that migratory birds perceive the Earth's magnetic field with the help of a receptor that uses ferromagnetic material (e.g., ferro-magnetite particles found in birds' beaks) to detect the inclination of the magnetic field. However, this mechanism seems to be used by adult birds that have made at least one migratory journey. Experimentally, this mechanism can be disrupted by applying a strong magnetic pulse, which can magnetise the ferromagnetic material in the opposite direction.

To test their hypotheses, the researchers experimented with European robins, which they caught and divided into two groups: the experimental group was placed in a special device and received a strong magnetic pulse, while the control group was placed in the same device without receiving the pulse. It is noted that both groups consisted of both adult and juvenile birds before their first migratory journey. After the intervention, robins were released into their natural environment and the researchers monitored 
them, through radio transmissions that researchers had applied on the robins, until the moment of their departure.

The results of this study showed that the orientation of the adult birds of the experimental group was disturbed by the magnetic pulse and in particular, a significant deviation of their orientation was found in comparison with the respective control group. In contrast, the orientation of the juvenile birds on both groups (experimental and control) did not differ significantly after the researchers' intervention.

Therefore, the researchers claim that robins have a receptor with magnetic properties, which plays an important role in their orientation during the migratory period; especially for the adult robins that seem to have developed a "magnetic map" after their first journey.

\section{Account B}

Brief description of the study conducted by the researchers $R$. Wiltschko, D. Gehring, S. Denzau, C. Nießner, and W. Wiltschko (2014) of the Goethe-Universität Frankfurt in Germany.

Researchers claim that migratory birds perceive the Earth's magnetic field with the help of a photoreceptor (it is called cryptochrome and is a type of protein), which is found in birds' eyes, is sensitive to blue light and allows them to receive information about the directions of the magnetic field, through appropriate biochemical reactions. Experimentally, this mechanism can be disrupted if the birds are in a closed environment with green light and especially when they have been kept in a dark environment before (because biochemical reactions cannot be completed).

To test their hypotheses, the researchers experimented with European robins that they caught and tested their orientation under different types of light (wavelengths) during the migratory period. The researchers applied two different experimental conditions. In the first condition, each bird was kept for an hour in a dark environment and then exposed to different wavelengths (blue, turquoise, and green light). In the second condition, each bird was exposed twice in succession to the same wavelength (blue, turquoise, and green light, respectively), without being kept in a dark environment. The same birds formed the control group, which were exposed only once to the green light, without being kept in a dark environment. In order to record their movements and orientation, the birds were placed in specially designed cages.

In the first condition, the results of this study showed that the robins were oriented appropriately for the season when exposed to the blue and turquoise light, but a significant deviation in their orientation was found when exposed to the green light. Similar results were found in the second condition, with the difference that only during the second exposure of the birds to the green light, their orientation was significantly affected. Finally, in the control group, the robins were properly oriented after their exposure to the green light.

Therefore, the researchers claim that robins have a photoreceptor that acts as a "magnetic compass" and allows them to receive information about their orientation during the migratory period, through the completion of biochemical reactions. 


\section{Appendix A2: Interview protocol(s)}

In the context of my doctoral dissertation, I study primary school teachers' views on historical and scientific topics that have been derived from the school subjects of History and Science of the $6^{\text {th }}$ grade. I would like to let you know that there are no right and wrong answers; because I am interested in how you think about these topics. I would like to note that your participation in this study is anonymous and the collected information will be exclusively used as research data in the context of this study. Could I have your permission to record our conversation?

\section{Questions about teachers' demographic characteristics:}

- How many years have you been working as a primary school teacher?

- How old are you?

- What studies have you done?

- Have you done postgraduate studies?

- Have you done any teaching (re)education/training?

- Have you participated in any research project, as a researcher?

- Can you determine (approximately) how many years you have taught in the 6th grade? When was the last school year?

Next, I would like you to read this text carefully (see Appendix A1 for each scenario), which will be the context of our conversation today. I would like to remind you that there are no right and wrong answers, and that I am interested in your personal view on the topic that we will address. You have as much time as you want.

\section{Open-ended questions after reading the scenario in history and science, separately (in a counterbalanced order):}

(Given that the questions for both topics and domains, history and science, were equivalent and in many cases exactly the same, the two interview protocols are presented at the same time, by noting the points where they differ with italics.)

- What do you think about the alternative views regarding the governance of Ioannis Kapodistrias/orientation of migratory birds based on Earth's magnetic field? (and/or) What is your opinion about the governance of I. Kapodistrias/orientation of migratory birds based on Earth's magnetic field?

- Do you think that these two accounts differ? If so, how?

- Could both accounts be correct? If so, could one of them be more correct than the other?

Questions for the participants who endorsed a particular point of view on this topic:

- How did you get to this point of view?

- Where do you base your point of view? Something else?

- Can you be sure that your view on this topic is correct? If so, how? If not, why not? Do you think that we will ever know for sure?

Questions for the participants who did not endorse a particular point of view on this topic:

- Could you (ever) say which was the better position? If so, how? If not, why not?

- What would you do/How would you think in order to decide on this topic?

- Do you think we will ever know for sure which is the better position? If so, how? If not, why not?

Questions for all participants

- In your opinion, can there be certainty about this topic? 
(and/or further) Can experts know with certainty the way of I. Kapodistrias' governing/how do migratory birds orient themselves based on Earth's magnetic field?

- When two people disagree on this topic, do you think that one is right and the other is wrong?

If yes, what does the word "correct" mean to you?

If not, can you say that one view is somehow better than the other? And why?

What does the word "better" mean to you?

- How is it possible that people have such different views on this topic?

- In your opinion, is there any connection between the different views on such a topic?

- How is it possible that experts/researchers disagree on this topic and come to different conclusions?

(and/or) The researchers who study this topic seem to come to different conclusions. How do you explain that?

- Could the conclusions of a third historian/group of scientists be different? If so, how? If not, why not? (The wording about "the historian" and "the group of scientists" is random and was used according to the composition of the research groups of the authentic studies.)

- Do you think that it is possible to have multiple different perspectives on this topic and all be correct?

- How could you personally judge the different perspectives on this topic? By what criteria?

- In your opinion, what does the knowledge about this topic consist of?

(and/or) What does the knowledge about this topic include?

- What is the structure/organisation of knowledge with regard to this topic?

(and/or) How do you imagine the structure/organisation of knowledge with regard to this topic?

- In your opinion, where does the knowledge come from for those who study this topic? (and/or) What is the source(s) of knowledge for those who study this topic?

- Is there anything else that you would like to add to what we have already discussed?

Transition from the topic-specific to the domain-specific level: Now, please imagine that you are asked to teach the governance of I. Kapodistrias/orientation of migratory birds based on Earth's magnetic field in the $6^{\text {th }}$ grade, in the context of the history/science lesson. Please, take for granted that you have access to both accounts and everything else you need; and neither the school curriculum nor the context determines how you will approach it. How would you go to teach this topic in the classroom with $6^{\text {th }}$-grade students?

\section{Open-ended (indirect and direct) questions about IBL in history and science education:}

- How does school history/science differ from historical/scientific research?

- Are there similarities between school history/science and historical/scientific research? Why (not)?

- Do you think that teachers should explain to their students how the knowledge included in their textbooks is produced?

(If yes) Are you trying to apply this to your classroom? If so, how?

- Do you think that school history/science should make students proficient in applying the reasoning skills that historians/scientists use to investigate the past/nature? Why (not)?

- What should students know and be able to do in the context of school history/science? Do you teach such skills in your classroom? If so, how?

- In your opinion, is inquiry a good approach to teach historical/scientific knowledge and skills? Why (not)?

(In case of asking the meaning of the word "inquiry", the same clarification about both history and science was given: i.e., searching, finding, studying and synthesizing multiple sources. Regarding school science, teachers were asked to direct answer this question twice, given that they defined inquiry through experiments, before being asked directly about the literature search.)

- Do you use this approach in your own lessons? 
If yes, please describe how you apply inquiry in your classroom.

- How would you define IBL in the context of school history/science?

- Where did you learn about IBL in history/science education?

- What do you consider to be the role of the students and what is your role in a lesson that focuses on IBL within school history/science?

- Do you choose IBL as an approach in the context of school history/science?

If applicable:

- What factors motivate you to foster IBL in your classroom (personal and external)?

- What difficulties do your students experience when engaging in IBL in the context of school history/science?

- What difficulties do you encounter when preparing, organising and facilitating IBL activities? 